\title{
BETTER SAFE HAVENS DURING COVID-19: A COMPARISON BETWEEN ISLAMIC AND SELECTED FINANCIAL ASSETS
}

\author{
Hedi Ben Haddad ${ }^{1,2}$ and Nader Trabelsi ${ }^{2,3}$ \\ ${ }^{1}$ University of Sfax, Tunisia, hedi.benhaddad@yahoo.fr \\ ${ }^{2}$ College of Economics and Administrative Sciences/ IMSIU, Saudi Arabia \\ ${ }^{3}$ LARTIGE/University of Kairouan, Tunisia, nhtrabelsi@imamu.edu.sa
}

\begin{abstract}
This study examines the safe haven properties of six assets (the S\&P Technology Index, S\&P GSCI Commodity Index, bitcoin, the Dow Jones Islamic Equity Index, the Dow Jones Global Sukuk Index and US Treasury bonds) during contiguous infectious diseases, employing the equity index returns of three regional markets (S\&P500, S\&P Europe, and S\&P Asia-Pacific) over the period 2010 - 2020 Q2. In the research, information-rich methodological tools such as the Markov switching approach and the DCC-GARCH model are used. Our results suggest that Sukuk and bonds act as safe havens for different types of investors during the ongoing COVID-19 crisis. This property is, however, is not confirmed for the S\&P Technology Index, Commodity Index, bitcoin or the DJ Islamic Equity Index. Moreover, using the time-varying VAR model and the new measure of pandemic uncertainty proposed by Baker et al. (2020), the results demonstrate that the COVID-19 pandemic has led to uncertainty and heightened volatility spillovers among regional equities and the safe haven assets examined. The key results of the study are robust and useful for portfolio managers and investors.
\end{abstract}

Keywords: Safe haven, Hedge, COVID-19 pandemic, TVP-VAR, Markov switching approach. JEL classification: G11; G15.

\author{
Article history: \\ Received : October 7, 2020 \\ Revised : February 28, 2021 \\ Accepted : March 15, 2021 \\ Available online : March 31, 2021
}

https://doi.org/10.21098/jimf.v7i0.1343 


\section{INTRODUCTION}

\subsection{Background}

At present, it is unknown how long the coronavirus outbreak will last. The situation will impose additional pressure on medical and economic authorities in their focus on reducing damage from the virus and finding satisfactory answers to the pressing questions in different areas (e.g., the social economy, health, and education). This study attempts to address one of the questions that is of concern to the various owners of capital, namely where they should invest their wealth, as the current pandemic has forced economies around the world to lock down.

Previous studies have recognised that gold (e.g., Baur \& Lucey, 2010); U.S. Treasury bills and bonds (e.g., Hartmann, Straetmans \& de Vries, 2004; Noeth \& Sengupta, 2010; Fleming, Kirby \& Ostdiek, 1998; Baur \& McDermott, 2010; Chan, Treepongkaruna, Brooks \& Gray, 2011); and U.S. dollars (e.g. Kaul \& Sapp, 2006) possess better properties as safe havens during stock market crises. After the global financial crisis (GFC-2008), there was also discussion about how Shariacompliant assets could be considered as a potential safe haven to protect investors from downturns in conventional markets (e.g., Shahzad et al., 2019)1 ${ }^{1}$. Other studies have found support for the safe-haven properties of cryptocurrencies during stock market turmoil (e.g., Urquhart \& Zhang, 2019; Stensås, Nygaard, Kyaw \& Treepongkaruna, 2019; Shahzad et al., 2019). The question that needs answering is whether these assets continue to act as safe havens during the ongoing COVID-19 pandemic crisis.

As far as we know, the current social and national distancing has had a profound effect on people's lifestyle. It is possible that the situation will influence the financial behaviour of investors and will ultimately threaten most parts of the global financial system, since the patterns of financial flows between domestic and international financial entities will be affected and may be different to those examined during previous crises. This has motivated our reexamination of the properties of several popular safe-haven assets in light of the COVID-19 economic conditions not experienced in nearly a century.

Although COVID-19 has quickly spread arounf the world, the exposure and safety measures adopted by governments differ from one country to another. This also motivates our consideration of the regional context of investors to better understand the properties of the assets.

There is ongoing debate on the behaviour of several assets and whether they are safe havens during the ongoing COVID-19 crisis. However, most of the articles surveyed in this paper (see the literature review) focus more on traditional assets (i.e. bonds, treasury bills, gold etc.) and bitcoin. Islamic financial assets (e.g., Islamic equity assets or Sukuk) have received less attention. This study intends to narrow this literature gap.

1 Under Sharia, five main criteria differentiate Islamic assets from their conventional counterparts: 1) the prohibition of riba (usury); 2) transactions must be free from gharar; 3) the core business of the firm must be in line with Sharia guidelines; 4) the requisite of joint proprietorship; and 5) each transaction must be associated with a tangible asset. 


\subsection{Objective}

The objective of the study is to contribute to the literature in two ways. First, we examine the properties of three assets yet to be examined in recent work (i.e., the Dow Jones Global Sukuk index ${ }^{2}$, the Dow Jones Islamic Equity Index, and the S\&P Technology Index), together with three other assets which have already been examined (the S\&P GSCI Commodity Index, U.S. Treasury bonds and the Bitcoin Index). In fact, it is well known that during past crises (e.g., the $1987 \mathrm{crash}$, and the GFC-2008) government bonds and precious metals were secure investments to reduce the risk of portfolios. After the GFC-2008, many studies have argued that Islamic financial institutions have been relatively more stable than conventional ones. The GFC presented the Sharia-compliant financial industry as an alternative safe haven. On the other hand, most analysts agree that the growing popularity of the crypto market can, in extreme cases, serve as a safe haven against bubbles and crashes. For many analysts, the tech group remained relatively stable during the rebound. Because of their massive market capitalisations, technology stocks still command the largest weighting in many of the indexes. Therefore, it could be asked whether these factors have motivated the birth of a new safe haven, specific to the ongoing COVID-19 pandemic crisis?

Second, we use the Markov switching approach to investigate the role of each asset as a hedge or safe haven for three regional stock market risks (S\&P 500, S\&P Europe, and S\&P Asia-Pacific). This approach has two main practical and conceptual advantages. First, the different states of the discrete processes can be identified as different volatility regimes. Secondly, the parameters can be easily interpreted. Finally, we use the popular DCC-GARCH model to estimate conditional covariance matrices for effective optimal portfolio designs and hedging ratios.

The remainder of the paper is structured as follows. Section II comprises a review of the background theory and literature, while Section III discusses the data, model development and methodology adopted for the estimation. Section IV presents an analysis of the results and finally Section V concludes the study.

\section{LITERATURE REVIEW}

\subsection{Background Theory}

The modern portfolio theory, pioneered by Markowitz (1952, 1959), asserts that an investor can reduce the risk of losses by diversifying into a large number of assets of different classes that are negatively correlated. The optimisation problem is expressed by the criteria of either the highest return at a certain level of risk or the least risk for a certain level of return.

Several authors have proposed advances to this theory. For instance, Sharpe (1964), Lintner (1965) and Mossin (1966) developed the general

\footnotetext{
2 It is worth mentioning that the aim difference between Sukuk and conventional bonds can be found in the following definition: 'sukuk are certificates of equal value representing undivided shares in ownership of tangible assets, usufruct and services, or (in the ownership of) the assets of particular projects. The returns on the certificates are directly related to the returns generated by the underlying assets. (The Islamic Finance Bulletin/King Fahd University of Petroleum and Minerals, 2016).
} 
equilibrium version, called the capital asset pricing model (CAPM). In this model, beta is the basic measure of risk. Samuelson (1969) and Merton (1971) also developed the continuous-time version, which had a deep impact on option pricing theory. In contrast to the mean-variance portfolio choice procedure, this theoretical development expressed the optimisation problem of portfolio choice in terms of maximising the expected total utility.

In relation to the early decades, an in-depth analysis of the literature reveals many other variants of optimisation problems. A number of these variants are related to market frictions such as transaction costs, borrowing and short-sales constraint, and saving behaviour (e.g., see Constantinides, 1986; Heaton \& Lucas, 1997; Gârleanu \& Pedersen, 2016), while others have profited from the advances in financial mathematics to develop algorithms more suitable to market reality. For instance, Rom \& Ferguson (1993) and Huang (2008), among others, suggest alternate measures of risk in place of variance, recognised by the downside risk approach. In this way, Rockafellar and Uryasev (2002) introduced expected shortfall or conditional value at risk to measure the downside risk. Rasiah (2012) proposed another alternative measure of risk that weights downside and upside risks differently.

These alternative measures have been proven to be the most coherent risk measures in financial crisis conditions. In such conditions, the behaviour of investors and assets can be also changed. In fact, investors often look for a refuge (i.e. a safe haven) to avoid unexpected risks. According to Baur and Lucey (2010), the refuge or safe haven is an asset that is uncorrelated or negatively correlated with another asset in episodes of market turbulence. On the other hand, an asset is viewed as a hedge if it exhibits an average negative or close to zero correlation with another asset. Baur and McDermott (2010) also distinguish between strong and weak forms of the hedge and safe haven property. More precisely, on average it is a strong (or weak) hedge asset if the correlation is negative (or close to zero) with another asset, while a strong (or weak) safe haven is an asset that is negatively correlated (or uncorrelated) with another asset in times of falling stock markets.

\subsection{Previous Studies}

The impact of COVID-19 on financial markets has naturally attracted the attention and interest of several authors. Bouri, Cepni, Gabauer and Gupta (2020) examined the return connectedness across five asset classes (i.e., gold, crude oil, the MSCI World Index, U.S. dollar index, and bonds). After the COVID-19 outbreak, they found that the total connectedness spikes and the structure of the network of connectedness changed. Furthermore, Cheema, Faff \& Szulczuk (2020) and Corbet, Larkin \& Lucey (2020) examined the influence of the ongoing COVID-19 pandemic on the safe-haven properties of several liquid assets (i.e. such as U.S. Treasury bills, U.S. Treasury bonds, U.S. dollars, and cryptos) against either stock market or cryptocurrency losses. They showed that U.S. Treasury bills and bonds and U.S. dollars generally acted as strong safe havens against stock market losses and weak safe havens against cryptocurrency losses. However, as Goodell and Goutte (2021) argue, bitcoin futures and tether can act as safe havens, as they have moved negatively with equities during COVID-19 period. 
Liu, Manzoor, Wang, Zhang \& Manzoor (2020) evaluated the short-term impact of the coronavirus outbreak on 21 leading stock market indices. Their results show that most East Asian countries have experienced relatively more negative abnormal returns than other countries. There has also been an adverse effect of COVID-19 confirmed cases on stock index abnormal returns. Similarly, Zhang, Hu \& Ji (2020) found substantial increases in volatility in global markets ${ }^{3}$ due to the outbreak. There were also different relationship patterns between these markets before and after the pandemic announcement, while the policy reactions to contain the virus have created further uncertainties. Contrary to this study, which used general financial market data, Ramelli and Wagner (2020) made an examination of stock price reactions to the dramatic increase in infection counts from the pandemic. They found that the sectors that suffered the most losses were energy, retail trade and transport services, while the sector that gained the most was healthcare. For other sectors, such as the semiconductor industry and utilities, there were differences across regions (i.e., China and America). Furthermore, Albulescu (2021) considered both COVID-19 global and US figures and showed that the health crisis enhanced S\&P 500 realised volatility.

As reported by the Islamic Development Bank (ISDB) ${ }^{4}$, the current crisis should be an opportunity to fill the gaps and enhance the diversity of the Islamic finance industry, since the COVID-19 crisis has adversely impacted Islamic banks as well as conventional ones (given the similarity of their business model), together with non-profit institutions, such as awqaf and zaket. With regard to Islamic capital markets, to which sukuk are major contributors, in a recent and unique paper Yarovaya, Elsayed \& Hammoudeh (2020) demonstrated the safe haven properties of Islamic bonds (sukuk) during the pandemic, while the spillovers between conventional and Islamic stock markets became stronger. Additionally, COVID-19, oil and gold were strong predictors of conventional-Islamic markets spillovers, while bitcoin was not a significant determinant of these relationships. Concerning Islamic equity investments, as the second most significant proportion of the Shariah-compliant Islamic finance sector, Ashraf, Rizwan \& Ahmad (2020) report that, on average, all Islamic equity indices show negative returns, with considerably high volatility. Furthermore, the S\&P and D\&J Islamic indices outperformed their corresponding benchmark equity indices on a nominal as well as on a risk-adjusted basis (Sharpe ratio).

In relation to this small but growing body of literature, this study focuses on the impact of the pandemic on various assets, with particular concentration on the Islamic finance industry.

\footnotetext{
3 The top 10 list of confirmed cases have been selected (according to the data on 27 March, 2020) with Japan, Korea and Singapore). footnote not clear. does "confirmed cases' refer to Covid or global markets. If "top 10 ", why only three countries listed?

4 ISDB Group Report on COVID-19 and Islamic Finance.
} 


\section{METHODOLOGY}

\subsection{Data}

We considered the daily log returns of ten financial variables over the period 3 October 2010 to 2 July 2020, during which several serious infectious diseases occurred, including bird flu (2013-17), Ebola (2014-16), MERS (2014-20) and coronavirus (2019-20). To diagnose and treat these events we used a novel index (hereafter referred to as "EMV_F"), as suggested by Baker, Bloom, Davis, Kost, Sammon, \& Viratyosin (2020). Use of this index provides advantages over other studies that have investigated the impact of infections throughout history. Table 1 gives a description of the financial variables and their sources.

Table 1.

Description of Variables and Data Sources

\begin{tabular}{|c|c|c|}
\hline Variable & Acronym & $\begin{array}{c}\text { Data source } \\
\end{array}$ \\
\hline US S\&P 500 index & SP & https://www.spglobal.com/spdji/en/indices/equity/ \\
\hline S\&P Asia-Pacific index & ASP & https://www.spglobal.com/spdji/en/indices/equity/ \\
\hline S\&P Euro index & EURO & https://www.spglobal.com/spdji/en/indices/equity/ \\
\hline $\begin{array}{l}\text { US 10-Year Treasury } \\
\text { Constant Maturity Rate }\end{array}$ & BOND & https://fred.stlouisfed.org/series/DGS10 \\
\hline $\begin{array}{l}\text { S\&P500 Information } \\
\text { Technology index }\end{array}$ & TECH & https://www.spglobal.com/spdji/en/indices/equity/ \\
\hline $\begin{array}{l}\text { S\&P GSCI Commodity } \\
\text { index }\end{array}$ & COMD & https://www.spglobal.com/spdji/en/indices/commodities/ \\
\hline $\begin{array}{l}\text { Dow Jones Islamic World } \\
\text { index }\end{array}$ & DJIM & https://www.spglobal.com/spdji/en/indices/equity/ \\
\hline Dow Jones Sukuk Index & SKK & https://www.spglobal.com/spdji/en/indices/fixed-income/ \\
\hline Bitcoin Price Index & BTC & https://www.coindesk.com/price/bitcoin \\
\hline
\end{tabular}

\subsection{Model Development}

The econometric methodology involved two steps. First, we used a two-regime Markov Switching (MS(2)) model to examine the hedge and safe-haven properties of the selected assets of the overall sample. Second, we employed the DCCGARCH model proposed by Engle (2002) to estimate the dynamic correlations between the selected assets, as well as their dynamic volatilities, which were then used to construct the optimal portfolios.

\subsubsection{Hedge and Safe-Haven Investigations}

The MS (2) model is given by the following equation:

$$
R_{i, t}=\mu\left(S_{t}=s\right)+\theta\left(S_{t}=s\right) R_{j, t}+\sigma\left(S_{t}=s\right) e_{t}
$$

where $R_{i, t}$ and $R_{j, t}$ are the returns of assets $i$ and $j$ and $\mu\left(S_{t}=s\right)$ and $\sigma_{2}\left(S_{t}=s\right)$ are the regime-dependant conditional mean and volatility respectively. The slope 
coefficient $\theta\left(S_{t}=s\right)$ represents the hedge ratio at state $S_{t}$, which minimises the variance of a spot position. This can be expressed as:

$$
\theta\left(S_{t}=s\right)=\frac{\operatorname{Cov}\left(\mathrm{R}_{\mathrm{i}, \mathrm{t}}\left(\mathrm{S}_{\mathrm{t}}=\mathrm{s}\right), \mathrm{R}_{\mathrm{j}, \mathrm{t}}\left(\mathrm{S}_{\mathrm{t}}=\mathrm{s}\right)\right)}{\sigma^{2}\left(\mathrm{R}_{\mathrm{i}, \mathrm{t}}\left(\mathrm{S}_{\mathrm{t}}=\mathrm{s}\right)\right)}
$$

The MS (2) representation is attractive by allowing an asymmetric dynamic, reflecting the switching behaviour of the assets' returns when different volatilities are observed. The unobserved state variable $S_{t}$ follows a first-order Markovprocess, such that the current regime $S_{t}$ depends only on the regime one period ago, $S_{t-1}$ :

$$
P\left\{S_{t}=l / S_{t}=k\right\}=p_{l k}
$$

where $p_{l k}$ gives the probability that state $l$ will be followed by state $k$. For a two-state case, we can represent the transition probabilities by a $(2 \times 2)$ matrix. Each element in the transition matrix $p_{l k}$ represents the probability that regime $l$ will be followed by regime $k$.

$$
P=\left[\begin{array}{cc}
p_{11} & 1-p_{22} \\
1-p_{11} & p_{22}
\end{array}\right]
$$

State $S_{t}=1$ defines the low volatility regime, while state $S_{t}=2$ defines the high volatility regime.

Asset $i$ is a strong (or weak) hedge against asset $j$ if $\mu\left(S_{t}=1\right)$ is significantly negative (or zero, statistically insignificant). Similarly, asset $i$ is a strong (or weak) safe haven against asset $j$ if $\theta\left(S_{t}=2\right)$ is significantly negative (or zero, statistically insignificant). Finally, a diversifier characteristic is related to an asset that has a very weak positive $\theta\left(S_{t}=1\right)$.

\subsubsection{Optimal Portfolios}

We now show the implications of our previous results on the optimal portfolios. To this end, we estimated the DCC-GARCH model, and then constructed the hedge ratios and the portfolio weights. The estimation of the DCC-GARCH model involved two steps. In the first step, we estimated a univariate ARMA(1,1)GARCH(1,1) model:

$$
\begin{aligned}
& x_{t}=\delta+\theta x_{t-1}+\varphi \varepsilon_{t-1}+\varepsilon_{t}, \varepsilon_{t}=\sqrt{h_{t}} z_{t} \\
& h_{t}=\psi_{0}+\psi_{1} h_{t}+\eta \varepsilon_{t-1}^{2}
\end{aligned}
$$

where $x_{t}$ is a vector of $n=9$ variables of interest (SP, ASP, EURO, BOND, TECH, COMD, DJIM, SKK and BTC); $\delta$ is the conditional mean; $\varepsilon_{t}$ is the error terms with $z_{t}$ 
following a student-distribution ${ }^{5}$; and $h_{t}=V\left(\varepsilon_{t} / \Sigma_{t-1}\right)$ is the conditional variance with variance-covariance $\Sigma_{t-1}$.

In the second step, the estimation of the conditional correlations between the nine variables was calculated as follows:

$$
\begin{aligned}
& H_{t}=D_{t} R_{t} D_{t} \\
& D_{t}=\operatorname{diag}\left(\sqrt{h_{11, t}}, \cdots, \sqrt{h_{i i t}}, \cdots, \sqrt{h_{n n, t}}\right) \\
& R_{t}=\operatorname{diag}\left(\left(Q_{t}\right)\right)^{-0.5} Q_{t} \operatorname{diag}\left(\left(Q_{t}\right)\right)^{-0.5} \\
& Q_{t}=(1-\gamma-\theta) \bar{Q}+\gamma \varepsilon_{t-1} \epsilon_{t-1}^{\prime}+\theta Q_{t-1}
\end{aligned}
$$

where $H_{t}$ is the multivariate conditional variance; $R_{t}$ is the $(n \times n)$ is the timevarying conditional correlation matrix $\left(\rho_{i j, t}^{D C C}=\frac{q_{i j, t}}{\sqrt{q_{i i, t} q_{i j, t}}}\right)$; and $\bar{Q}$ is the $(n \times n)$ unconditional variance matrix.

The hedge ratios and optimal portfolio weights can be computed as follows:

$$
\begin{aligned}
& \beta_{i j, t}=\frac{m_{i j, t}}{h_{i i, t}} \\
& \omega_{i j, t}=\frac{h_{i i, t}-m_{i j, t}}{h_{i i, t}+h_{j j, t}-2 m_{i j, t}} \\
& \omega_{i j, t}=\left\{\begin{array}{c}
0 \text { if } \omega_{i j, t}<0 \\
\omega_{i j, t} \text { if } 0 \leq \omega_{i j, t} \leq 1 \\
1 \text { if } \omega_{i j, t}>1
\end{array}\right.
\end{aligned}
$$

where $\beta_{i j, t}$ and $\omega_{i j, t}$ are the time-varying hedge ratio and portfolio weight respectively. $m_{i j, t}$ is the conditional correlation between assets $i, j$, and $h_{i, i}$ is the conditional variance of asset $j$.

\section{RESULTS AND ANALYSIS}

\subsection{Descriptive Statistics}

From Table 2, it can be seen that bitcoin exhibits the higher volatility. The ERS unit root tests reject the null hypothesis of the unit root in the time-series of interest, suggesting that our variables follow stationary processes. Furthermore, the financial, currency, and commodity series investigated behave like an $\mathrm{ARCH}$ process, suggesting that GARCH specifications are appropriate for estimating the underlying conditional correlations and volatilities of the price returns series.

5 We used the student distribution, as the normality hypothesis was rejected for all price returns (Table 2, the Jarque-Bera, JB test). 


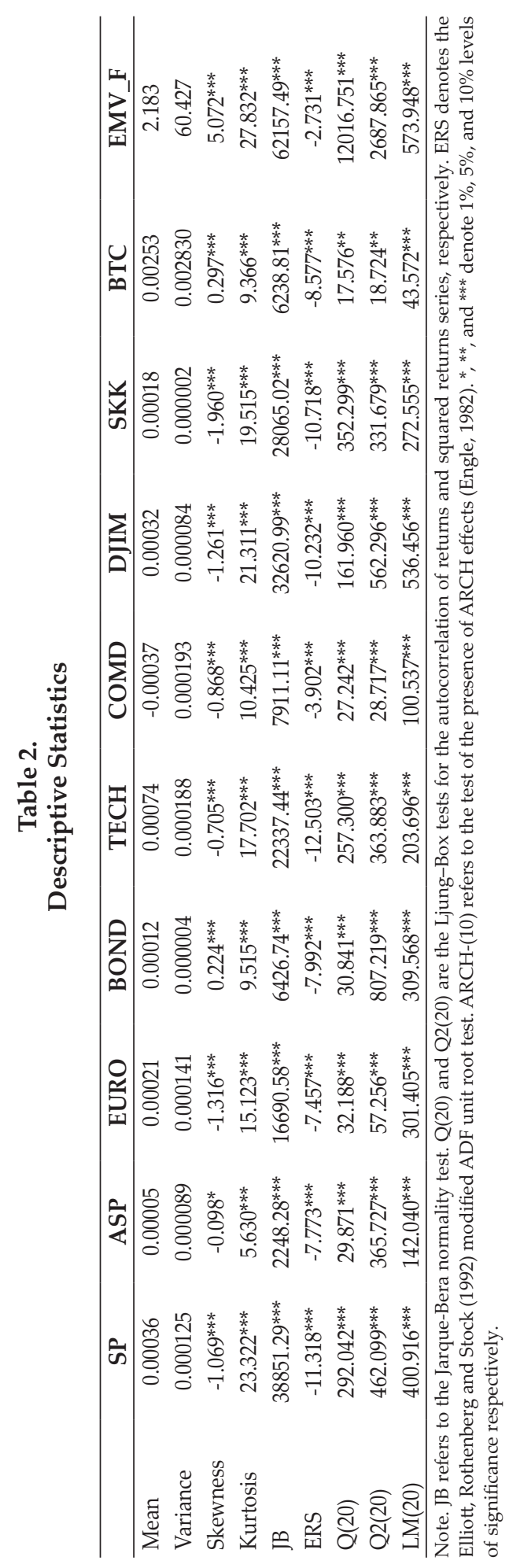


Finally, all the price returns were negatively-skewed time series and exhibited high values of kurtosis, indicating the presence of sharp peaks in these markets. The results of the ERS unit root tests indicate that we cannot accept the null hypothesis of the unit root. Therefore, all the daily returns behave like stationary processes.

Figure 1 shows that all the variables experienced sharp increases over the period spanning March 2020 to May 2020 (dates that correspond to a peak in COVID-19 pandemic cases recorded around the world).
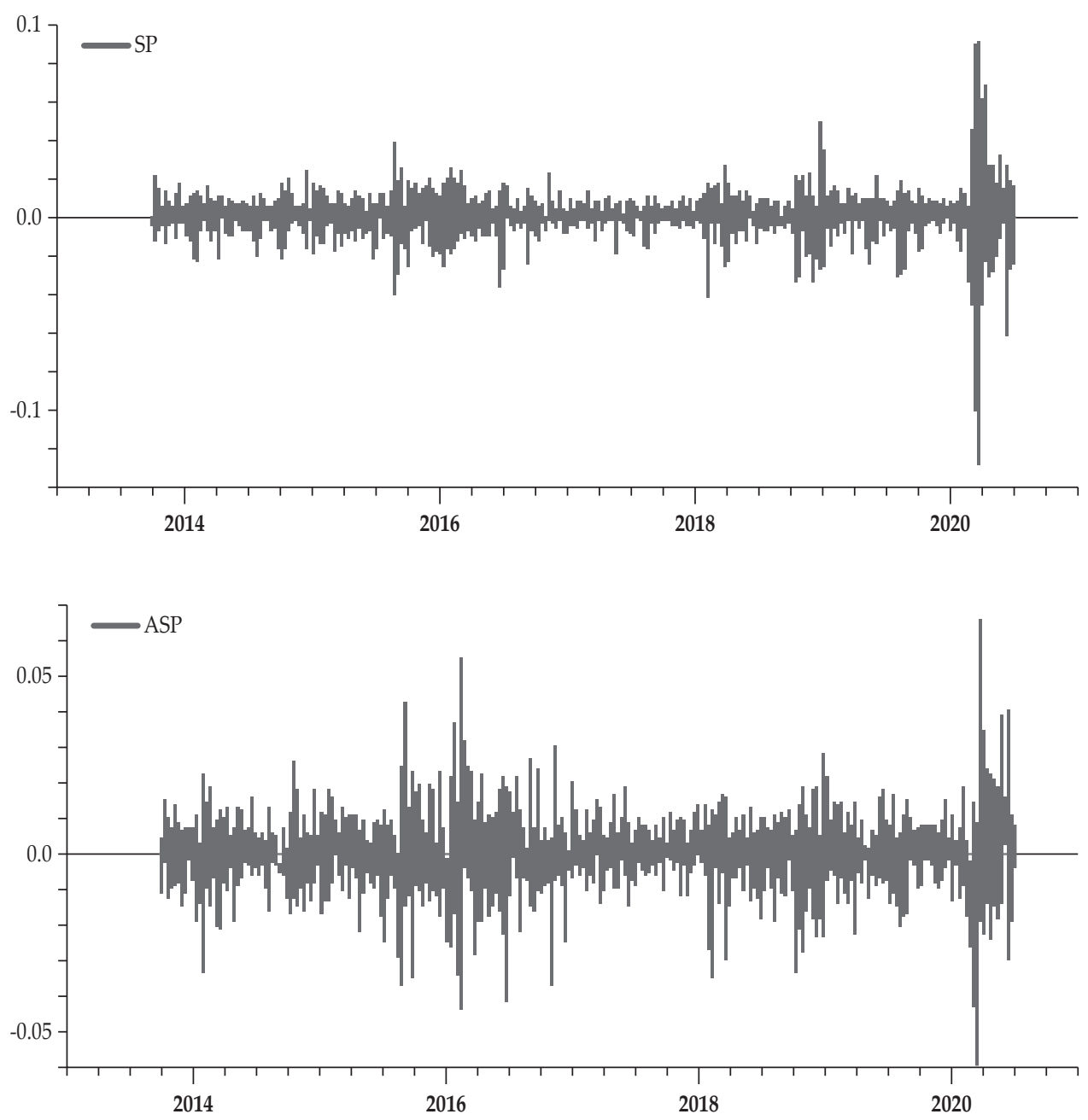

Figure1.

Time-series Trajectories of Returns 

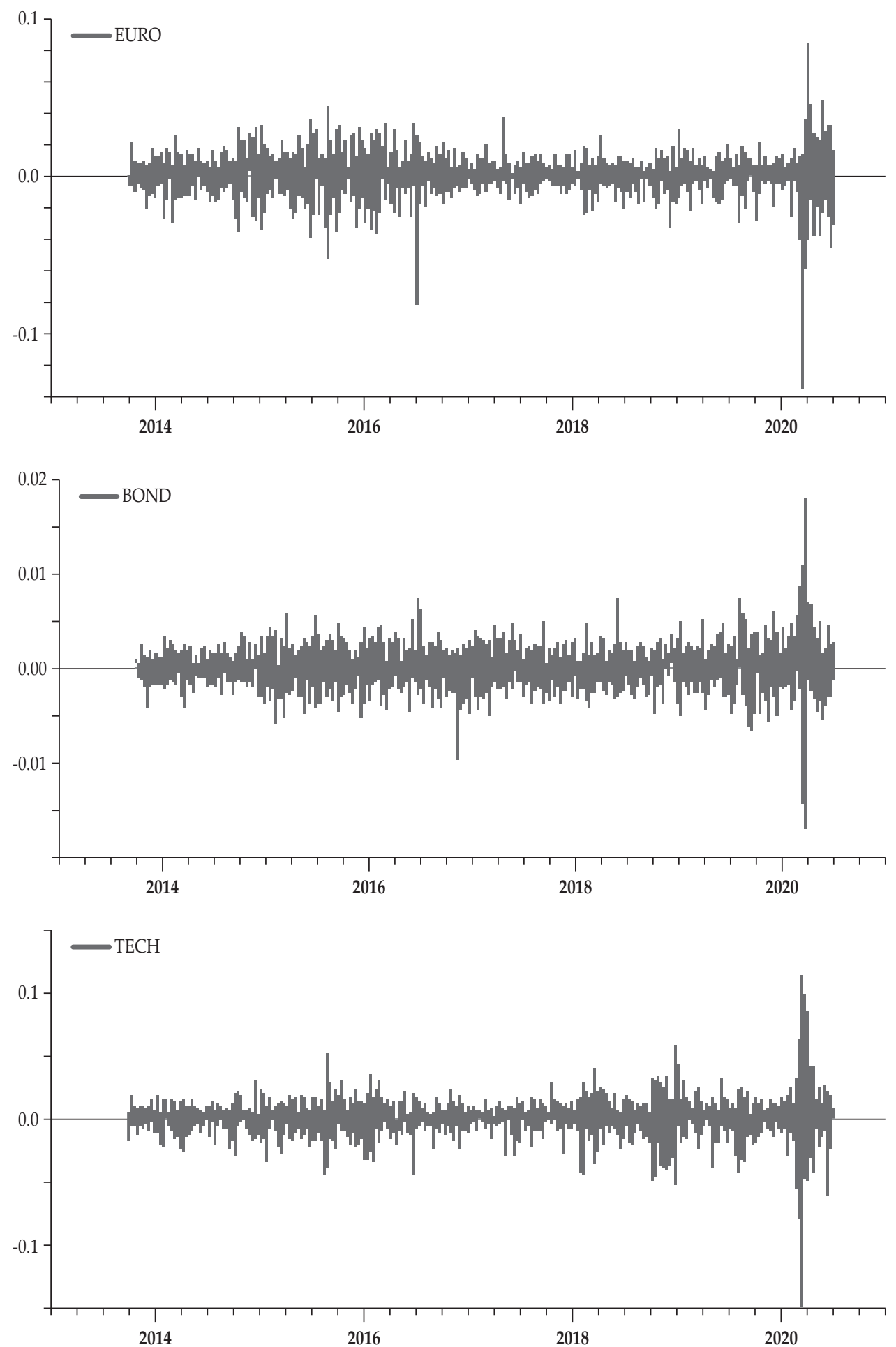

Figure1.

Time-series Trajectories of Returns (Continued) 

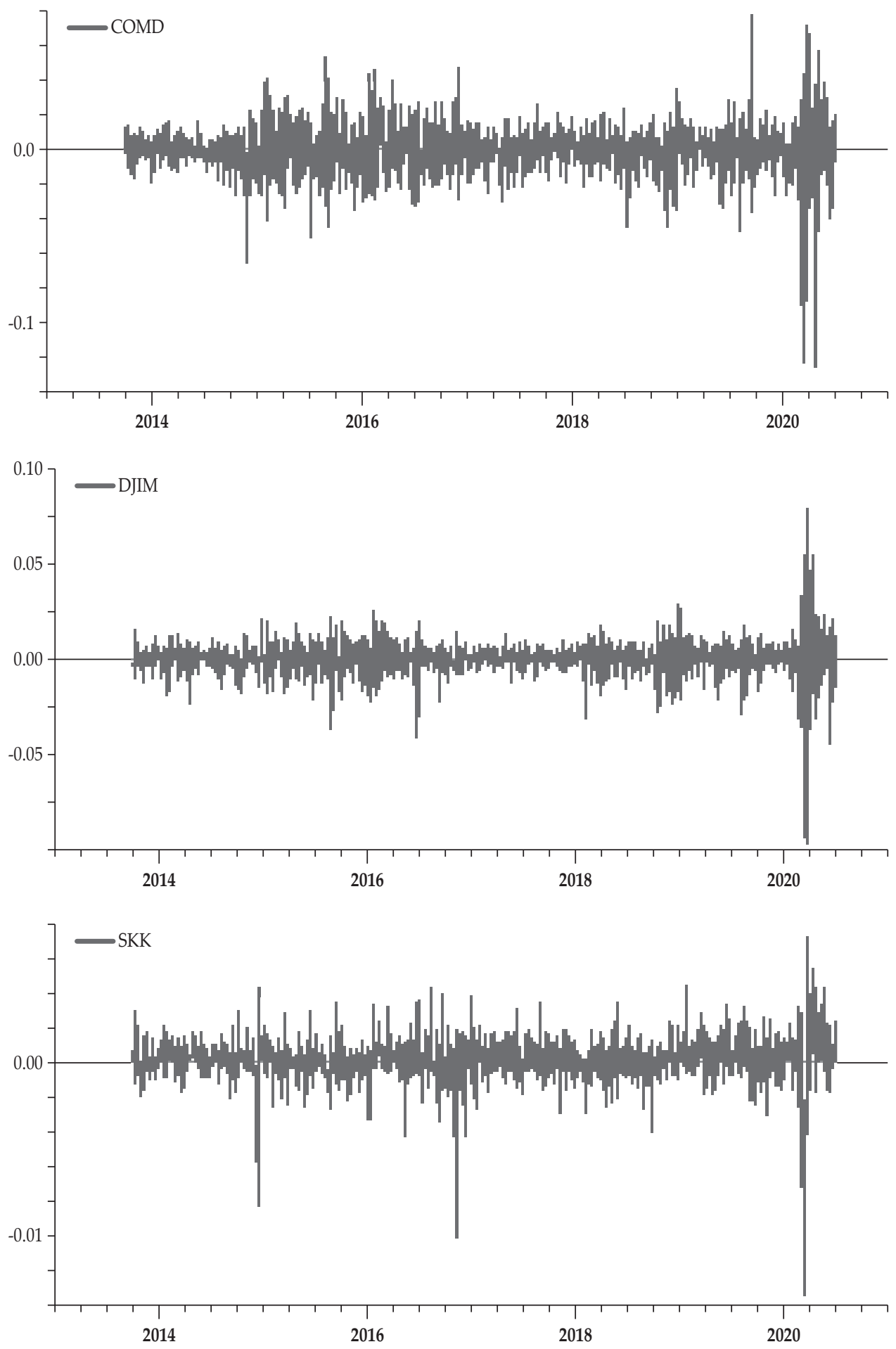

Figure1.

Time-series Trajectories of Returns (Continued) 


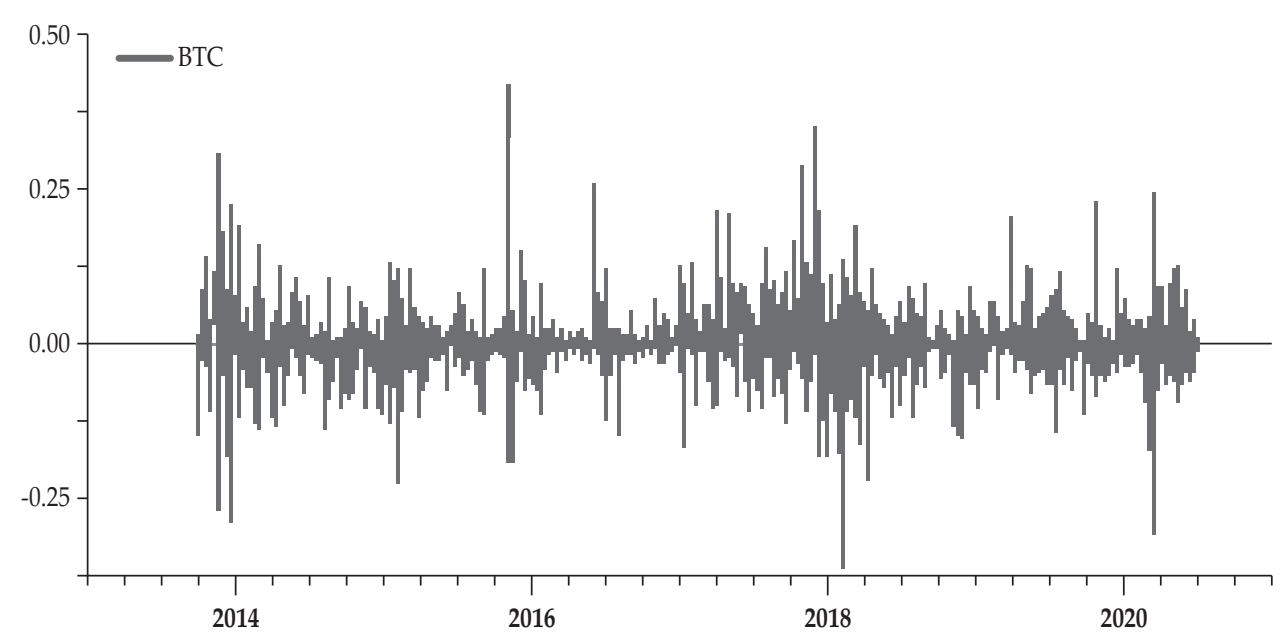

Figure1.

Time-series Trajectories of Returns (Continued)

\subsection{Results}

\section{a. Hedge and Safe-haven Investigations}

In the case of the SP-BOND pair, the $\theta$-coefficients are shown to be negative and statistically significant in a high volatility state (see Table 3 ). Additionally, the $\mu$-coefficient is close to zero in a low volatility state. These statistics indicate that in the case of the US market, government bonds act as a solid and effective diversifier, hedge and safe haven asset during times of expansion and recession.

The other selected assets can be also trusted as hedges (i.e., BTC, commodities and Islamic instruments) or diversifier assets (i.e., ASP, EURO and TECH) against SP fluctuations in normal conditions, but emerge as insignificant safe havens during periods of turmoil. An exception was recorded by BTC, with a weak and statistically insignificant coefficient, indicating its characteristic as a weak safe haven asset for US investors against past stock shocks. These results indicate that US investors prefer more secure and liquid assets during periods of crisis, regardless of their safety of principal and periodic interest payments. Therefore, these findings complement those of Baur and Lucey (2010) and Chan et al. (2011), which suggests that bonds possess better safe-haven properties than precious metals during stock market crises. Furthermore, our results related to bitcoin (BTC) are consistent with Conlon and McGee's (2020) findings, which show that bitcoin has indeed been a poor hedge against the SP500 during the COVID-19 crisis. 


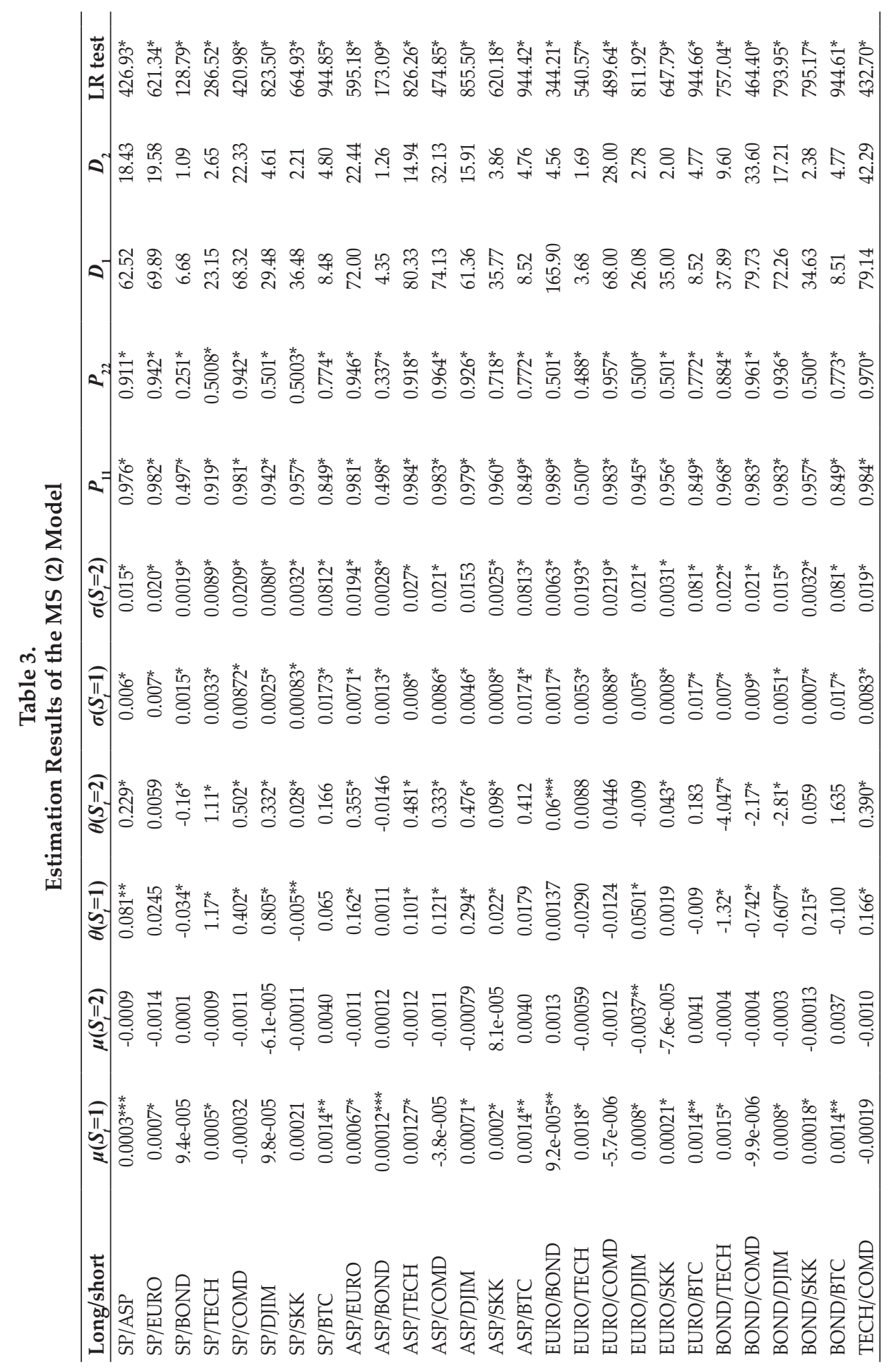




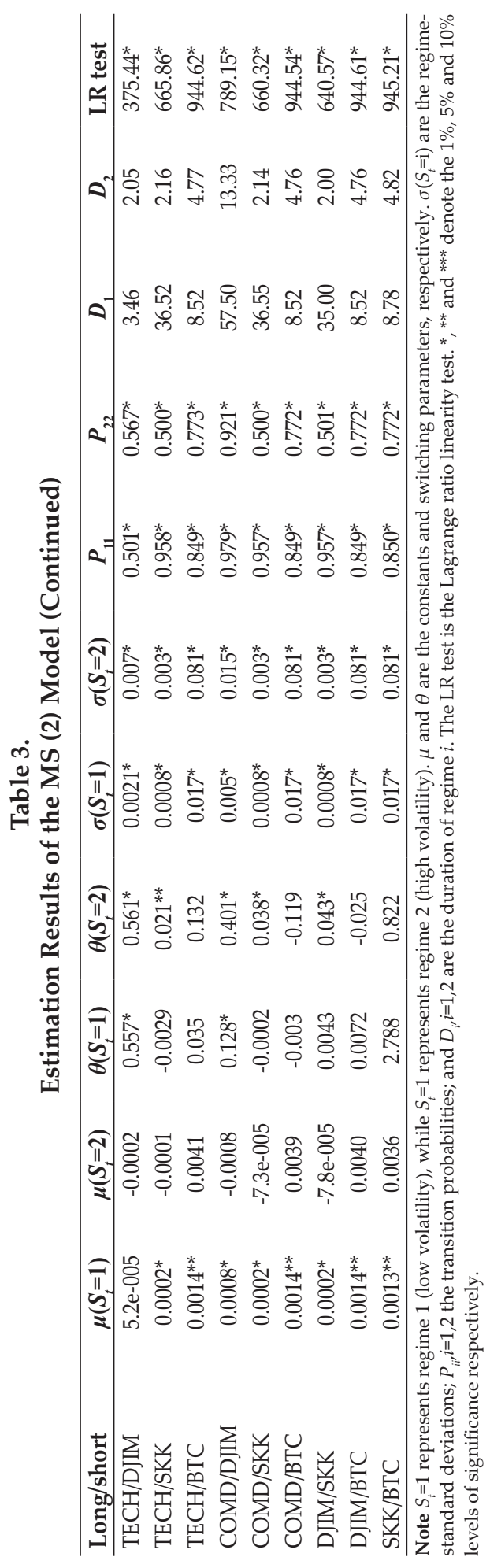


In Asian markets in a calm volatility state, we find that Islamic stocks and international stock indices (i.e., EURO, TECH, DJIM, SKK, BONDs and BTC) have played an important role in helping investors to diversify their expositions over the last decade. Furthermore, the estimates indicate weak evidence of COMD as a hedge. This result confirms the conclusion of Śmiech and Papież (2017), who found that gold could be a hedging instrument for stocks even during normal market conditions. On the other hand, gold has historically occupied a specific position in Asian society. It is also the most liquid savings instrument, since it can be converted into money easily and quickly. For instance, India's gold demand is large and accounts for one-third of global demand. Moreover, in a purely economic sense, gold has long been a store of value (Faugère, 2013), a hedge against inflation (Shahbaz, Tahir, Ali \& Rehman, 2014) and a means of diversification in terms of portfolio management (Sherman, 1986; McCown \& Zimmerman, 2006).

In high volatility states, there is no evidence that the selected assets are safe havens against Asian stock market fluctuations, apart from BONDs and BTC. It is worth noting that there is a common belief that sovereign bonds are the most canonical example of a safe-haven asset because of their lower realised volatility compared to stocks (Cheema et al., 2020). On the other hand, the empirical results concerning bitcoin during the ongoing health crisis are inconclusive. For instance, Goodell and Goutte (2021) underlined the safe-haven property of BTC, while Conlon and McGee (2020) came to an opposite conclusion. The preference of investors for bitcoin can be explained by the fact that, unlike conventional currencies, it is fully decentralised and independent of any central authorities. If the financial system is not working well or is under threat, investors seek refuge in bitcoin, which is independent from the financial system and its underlying technology. According to Ciaian, Rajcaniova \& Kancs (2016), bitcoin is also attractive as an investment, which is reflected in its increasing acceptance and trust; furthermore, lower transaction costs and uncertainty amongst investors increase investment demand for bitcoin.

Concerning European investors, TECH, BONDs, COMD and Islamic instruments (equity and Islamic bonds) provide weak hedges and diversifier assets in normal conditions. In abnormal ones (i.e., times of stress), these assets retain their properties and exhibit safe-haven performance alongside BTC. This result is important, as it weakens the view that after the sovereign debt crisis that hit the Eurozone countries has already caused investor behaviour. Accordingly, bonds have become less tractable for European investors. This can, however, reinforce the recent view supporting the effectiveness of TECH (i.e., US and China tech) in portfolio performance.

In 2008, the GFC reinforced the use of Islamic financial instruments by investors. The estimate results shown in Table 3 indicate that a reduction in Islamic stock expositions can be achieved by SKK or BTC during normal market conditions. Moreover, weak safe haven opportunities can be achieved by a long position on DJIM and a short one on BTC. However, given its positive significant coefficient during perturbed market conditions, SKK has lost its status as a hedge. According to Shahzad et al. (2019), the hedge and safe haven properties of SKK can vary over time. More precisely, they confirmed the role of SKK as a safe haven asset during 
the GFC, but not during the European debt crisis. Concerning the Islamic equity index, it is clear from Table 3 that it can act as a diversifier, hedge and safe haven against the risks of other different markets, defined by the TECH, BTC and COMD indexes. While SKK has the potential to be a good diversifier and hedge for most asset classes, it has a weak potential as a safe haven for bond investors, as they move together during crises. It is interesting to compare these results with those of Bhuiyan, Rahman, Saiti \& Ghan (2018), who found a higher correlation between the Malaysian sukuk index and the Singaporean-based fixed income index during the Eurozone crisis between 2011 and 2012.

Overall, a difference between the characteristics of the selected assets between regions and even between ethical and conventional investments can be seen.

\section{b. Portfolio Analysis}

There have been several extreme economic periods during the last decade (e.g., the 2010-2012 European Sovereign Debt, the mid-2014 oil crisis, the Ebola epidemic, the COVID-19 pandemic, etc.). Parallel to the body of literature discussing the effects of past crises on our selected assets, this study is one of the first to focus on how the recent COVID-19 crisis has impacted on their properties. In particular, we evaluate their significance in solving asset allocation problems (i.e., minimum variance portfolios and hedged portfolios) for different types of investor. To this end, we used the conditional variance parameter and the estimates of the DCCGARCH model, as presented in Figures $2 \mathrm{a}$ and $2 \mathrm{~b}$ (the shaded area is related to DCC in high volatility times). It can be seen that the dependence structure between pairs changes during stable and highly volatile times. A quick investigation of the plots confirms our previous findings and conclusions from Table 3 on the alternative investments of the selected assets for hedging and diversification.

It is worth mentioning that these pairwise DCCs will be used to establish whether the selected assets' proprieties are valid for different states. For this reason, we consider how to find the optimal hedge ratio and optimum risk portfolio weight for two sub-samples: the pre-COVID-19 pandemic period (Table 4) and the ongoing COVID-19 pandemic period (Table 5). We believe that the portfolio optimisation framework will provide further findings that our previous analysis was unable to reveal.

As shown in Tables 4 and 5, the results for the US optimal portfolio weights and US hedging strategies are similar. The estimates clearly demonstrate the existence of an effective hedging strategy incorporating a long position in BONDs or SKK, while the existence of a less expensive hedging strategy is related to BTC, but this is a poor effectiveness strategy, given that the HE is close to zero. A minimumvariance portfolio can be also achieved by shifting SP equity holdings to bonds or SKK. Bonds and SKK, therefore, appear to be the most effective way of protecting US investors during the ongoing COVID-19 pandemic period. These results are partially in line with the recent ones of Cheema et al. (2020), who suggest that more liquid assets can be more effective in reducing the exposition risk of US investors during the ongoing COVID-19 crisis. 

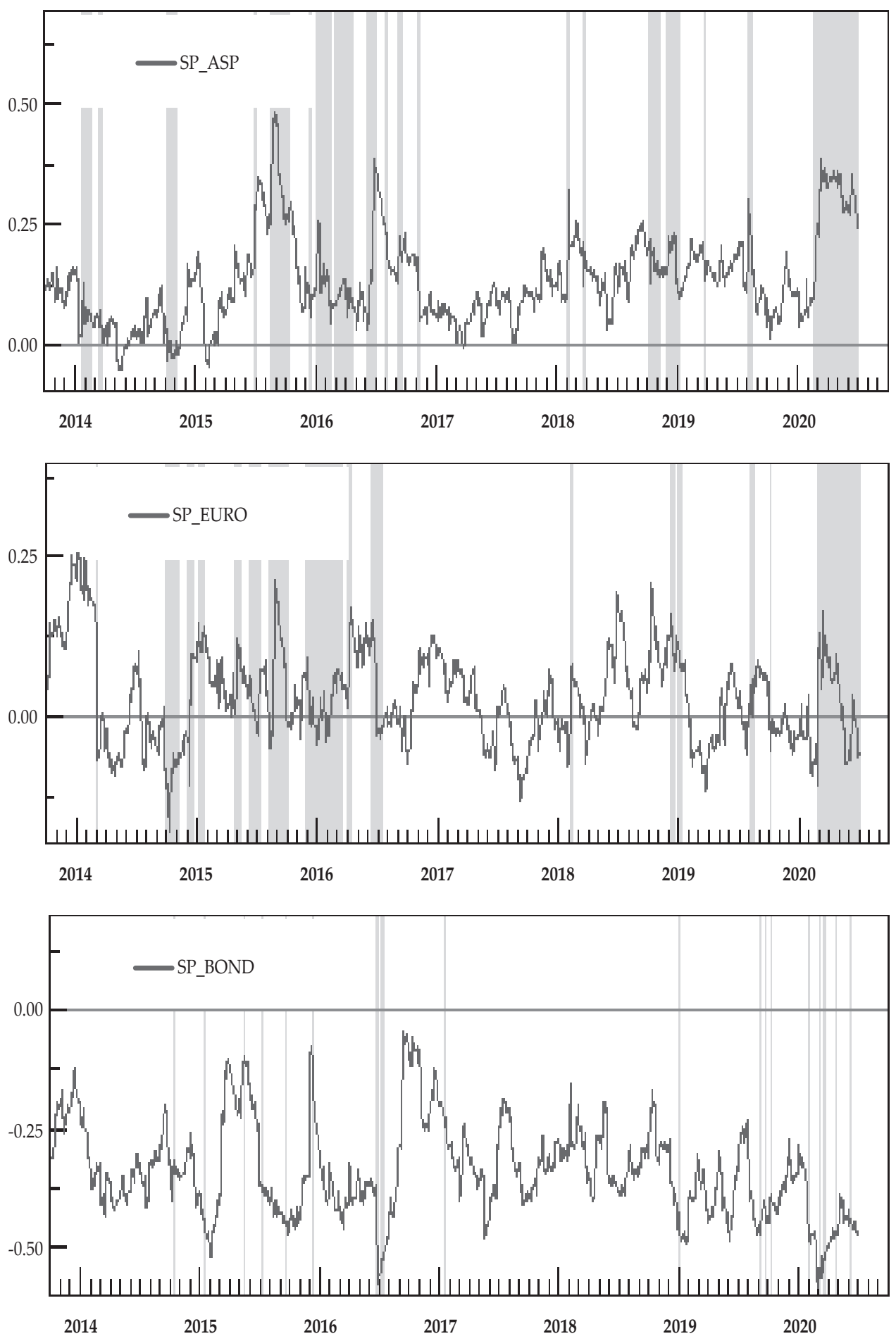

Figure 2a.

Estimated Dynamic Conditional Correlations. The Shaded Areas Correspond to the High Volatility Regime Period 

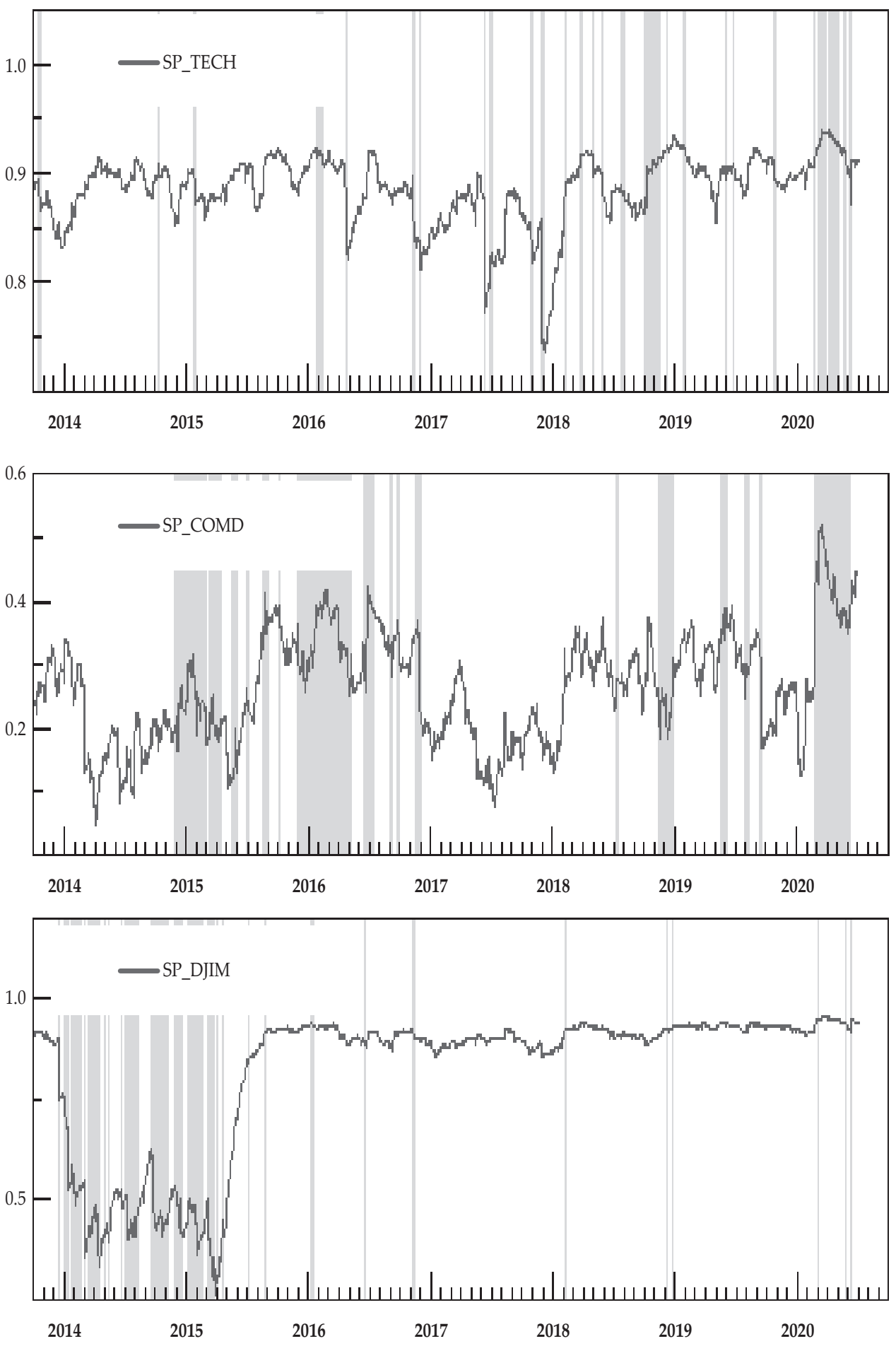

Figure 2a.

Estimated Dynamic Conditional Correlations. The Shaded Areas Correspond to the High Volatility Regime Period (Continued) 

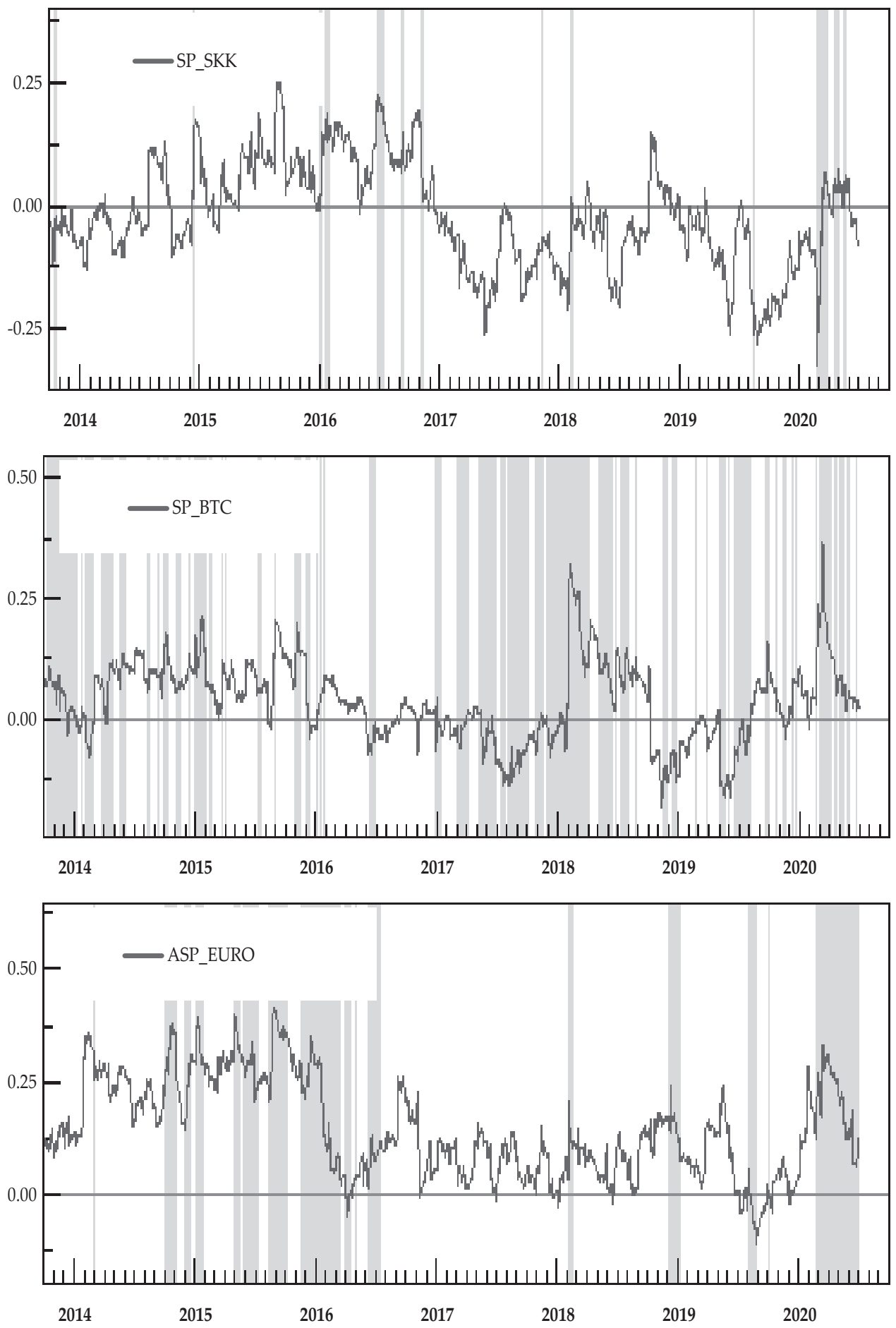

Figure 2a.

Estimated Dynamic Conditional Correlations. The Shaded Areas Correspond to the High Volatility Regime Period (Continued) 

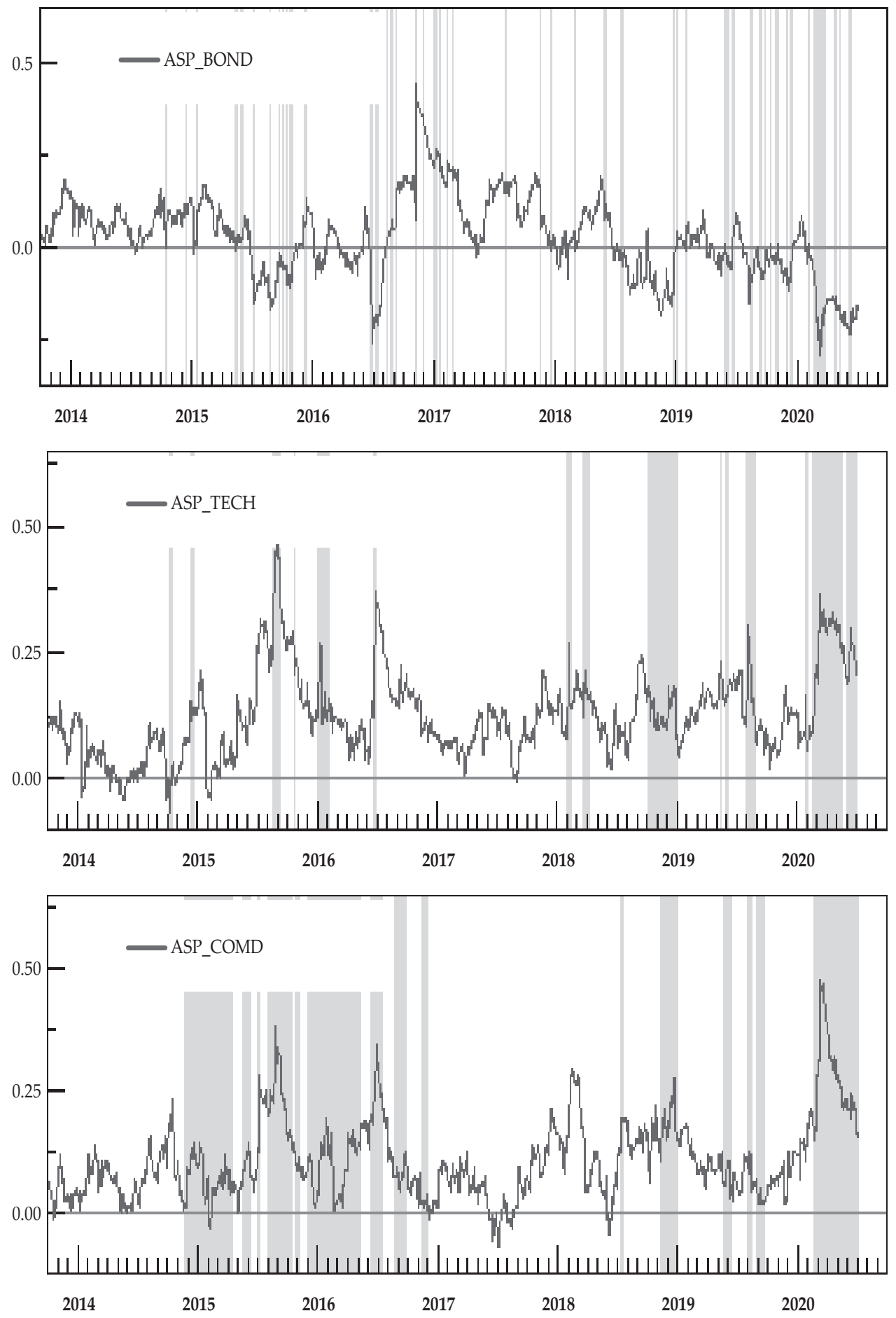

Figure 2a.

Estimated Dynamic Conditional Correlations. The Shaded Areas Correspond to the High Volatility Regime Period (Continued) 

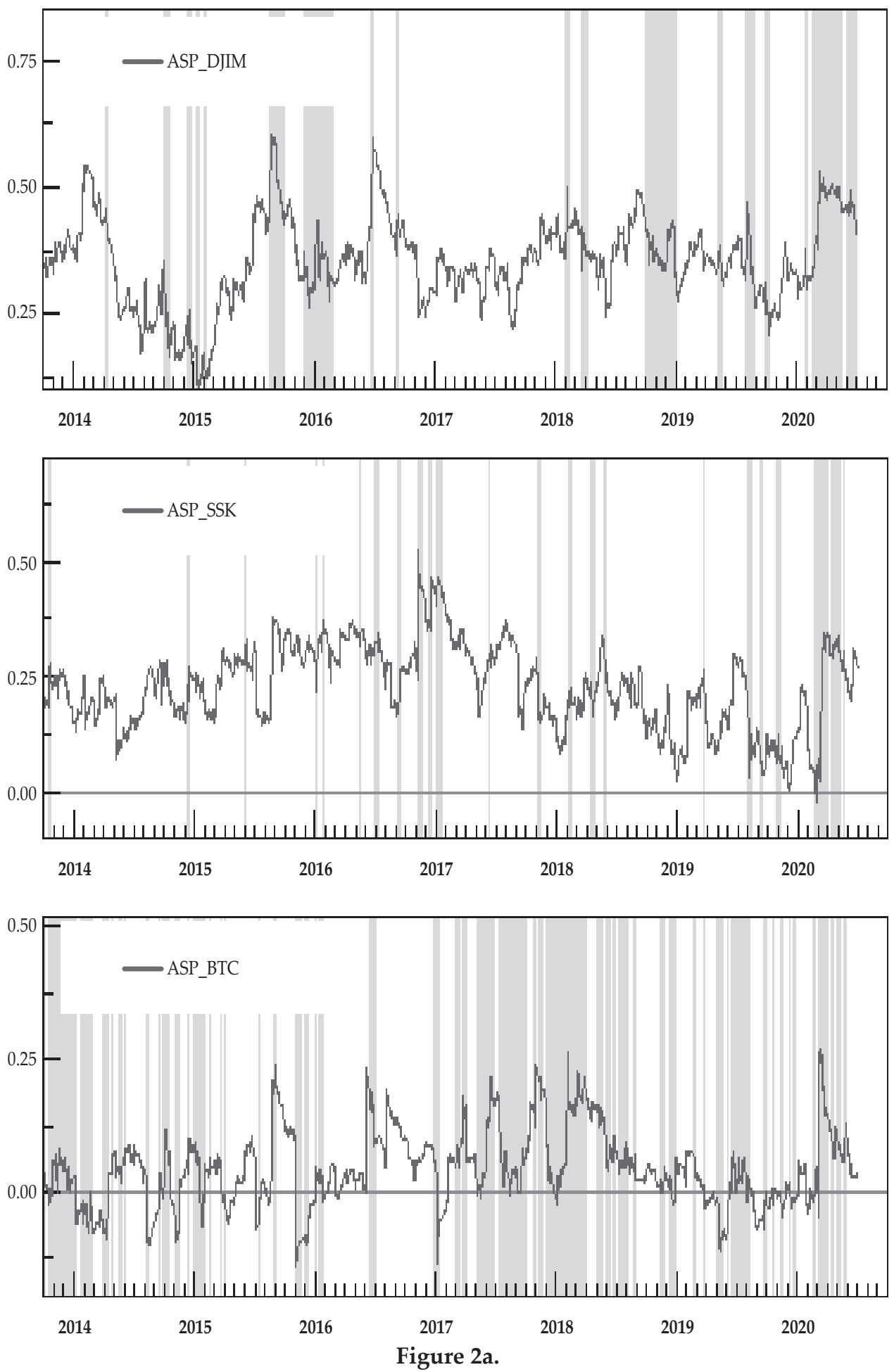

Estimated Dynamic Conditional Correlations. The Shaded Areas Correspond to the High Volatility Regime Period (Continued) 

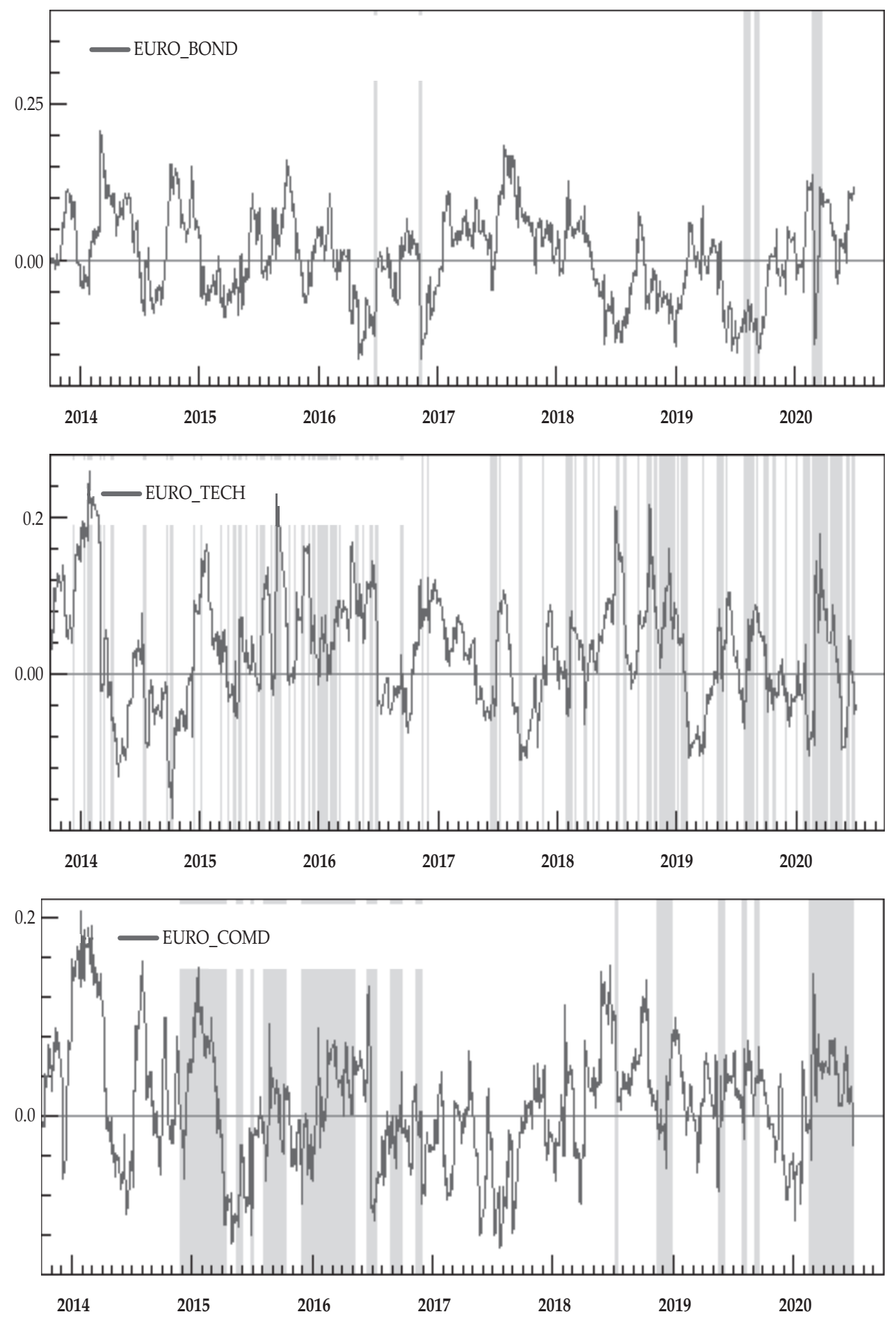

Figure 2a.

Estimated Dynamic Conditional Correlations. The Shaded Areas Correspond to the High Volatility Regime Period (Continued) 

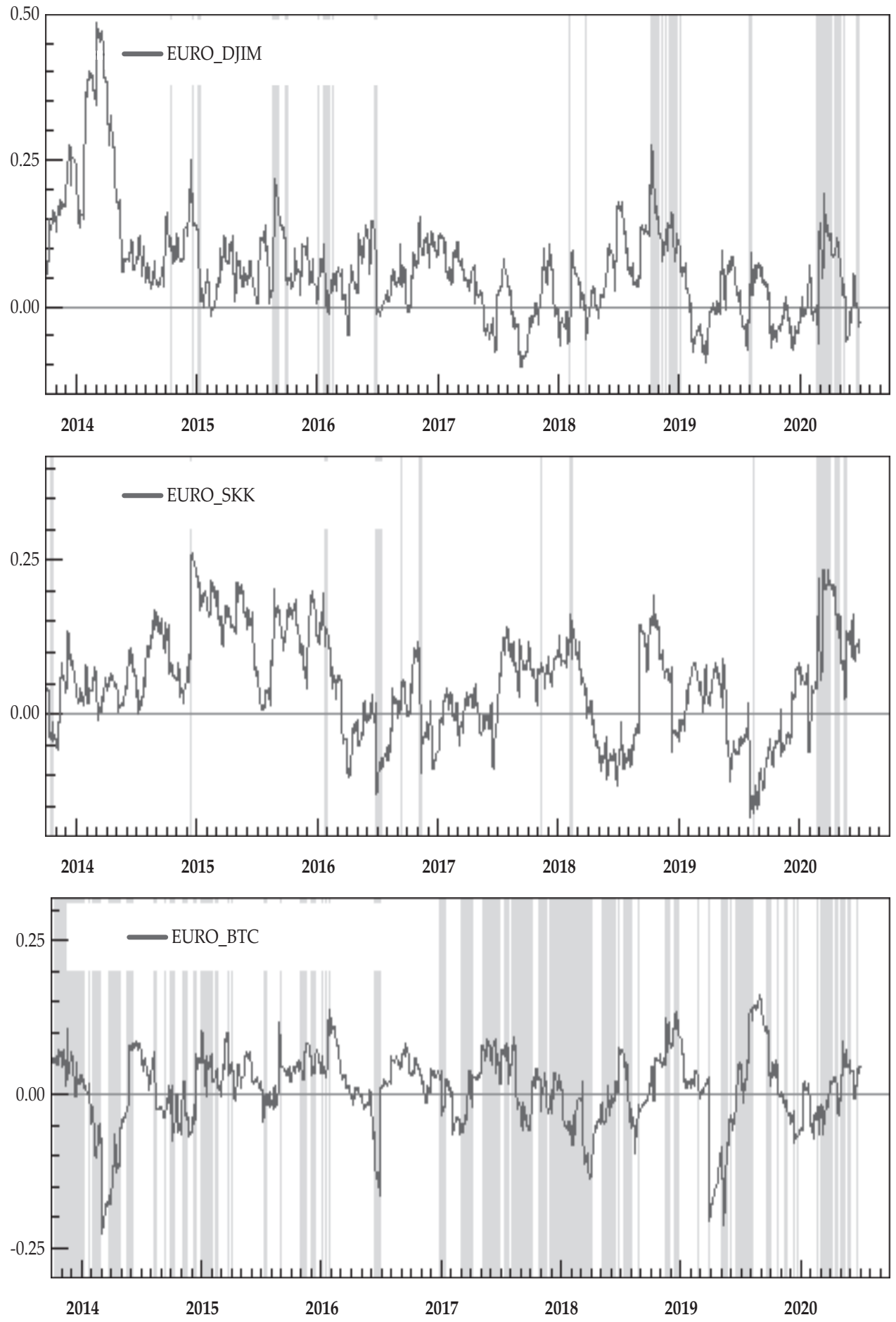

Figure 2a.

Estimated Dynamic Conditional Correlations. The Shaded Areas Correspond to the High Volatility Regime Period (Continued) 
A close look at the values of $\omega^{c}$ also indicate the stronger performance of bonds as diversifiers, hedges and safe haven assets for Asian stockholders over the last decade and during the current COVID-19 crisis. Similar results can be also seen for European stock markets. A comparison of Tables 3 and 4 shows the performance of bonds in reducing expositions and protecting investors against COVID-19 pandemic stock fluctuations for different regional investors. On the other hand, both Sharia-compliant assets (i.e., DJIM and SKK) can be hedge assets against TECH index fluctuations, while DJIM fails to confirm their safe haven property during the current crisis. In other terms, these finding indicate SKK to be a safe haven during the ongoing health situation in US markets (i.e., the SP and TECH indexes).

Regarding the behaviour of Muslim and non-Muslim investors, Table 4 shows that equity market risk could have been be reduced by diversification across SKK (34\%) and DJIM (66\%) before the COVID-19 crisis. Using the regime-switching student/normal copulas, Shahzad et al. (2019) suggest mixing Islamic stock and sukuk returns to generate profitable gains or to reduce expected losses.

Furthermore, Table 4 shows the existence of the flight-to-quality hypothesis during periods of turmoil, since traders have fled from Islamic stocks to Islamic bonds during the ongoing COVID-19 turbulent market conditions. Therefore, in view of the disruption caused by the pandemic, it would be advisable for Muslim investors to shift their holdings from DJIM to SKK. For example, the optimum level of SKK can become $66 \%$. Although they offer minimal hedging effectiveness during the past crisis, SKK can be viewed as superior safe-haven assets alongside BOND against the current rise in equity markets.

The additional information from Tables 4 and 5 indicates that SKK cannot serve as effective diversifiers or as a hedge for TECH investors, while they can be considered as a good safe haven for such investors during the ongoing COVID-19 crisis. This is a remarkable change in the behaviour of SKK, which is probably specific to the pandemic conditions. These results are important compared to those of previous studies that concentrate on the performance of Islamic finance compared to its conventional counterpart (e.g., Ashraf, 2013). 

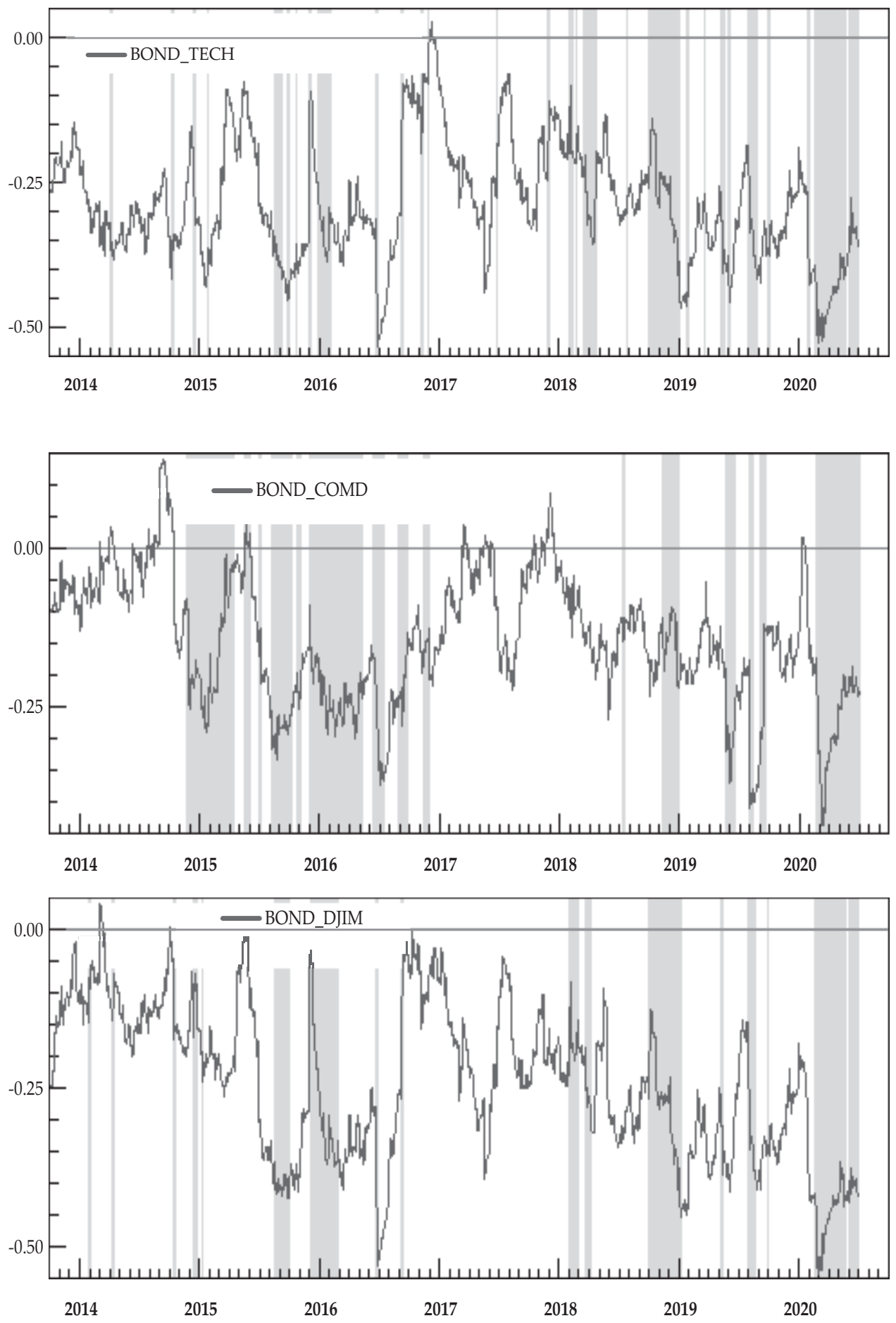

Figure 2b.

Estimated Dynamic Conditional Correlations. Shaded Areas Correspond to the High Volatility Regime Period 

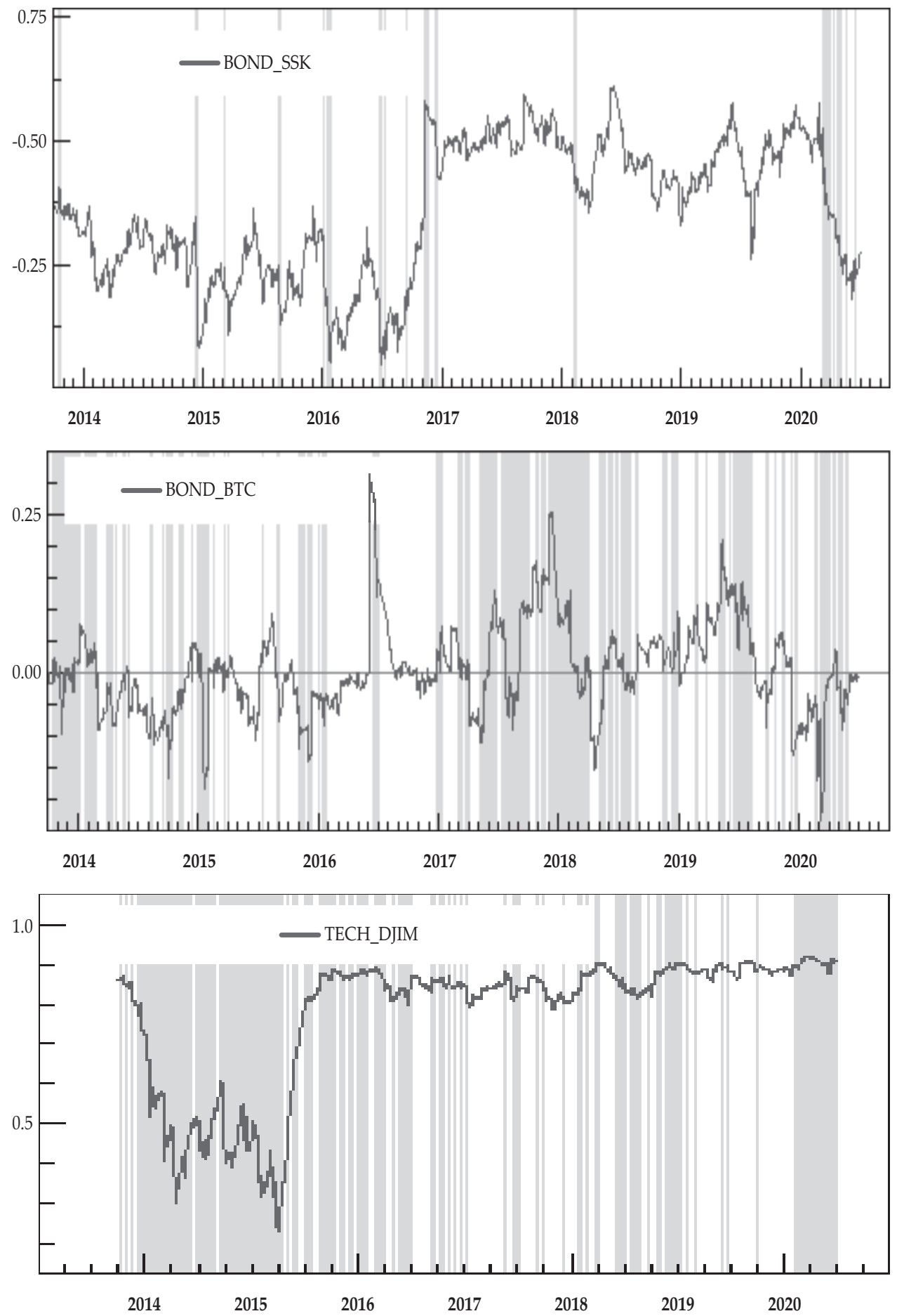

Figure 2b.

Estimated Dynamic Conditional Correlations. Shaded Areas Correspond to the High Volatility Regime Period (Continued) 

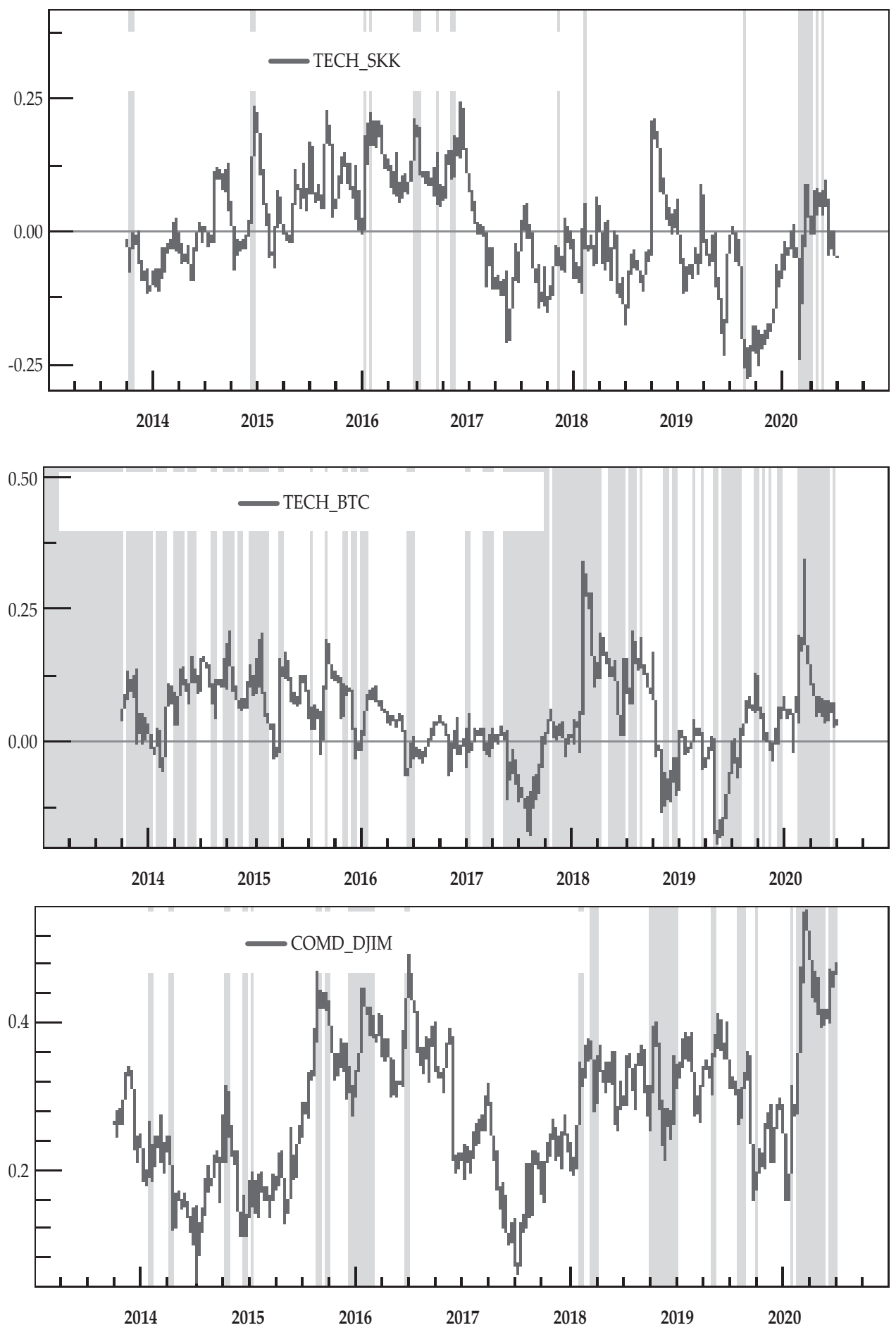

Figure 2b.

Estimated Dynamic Conditional Correlations. Shaded Areas Correspond to the High Volatility Regime Period (Continued) 

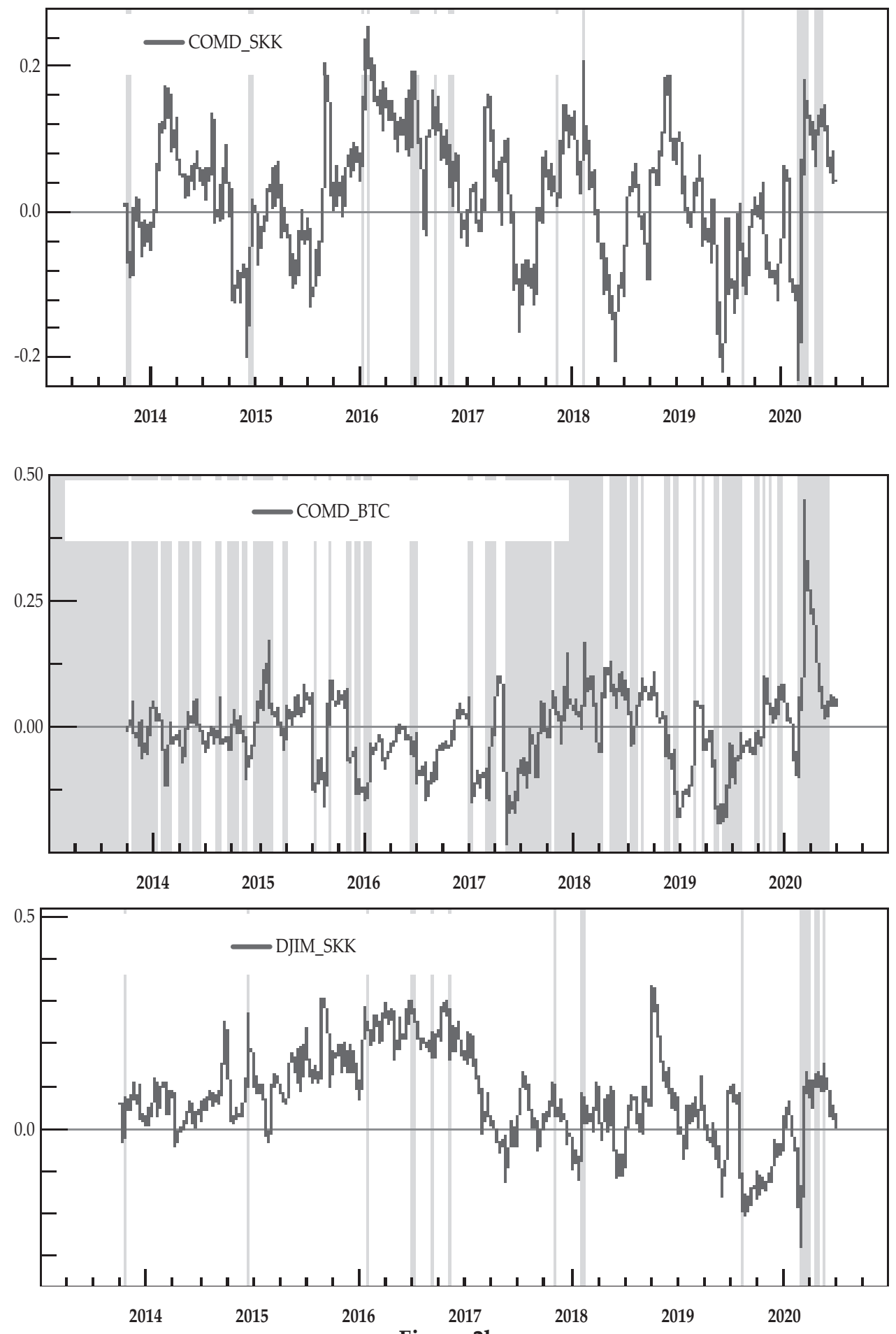

Figure 2b.

Estimated Dynamic Conditional Correlations. Shaded Areas Correspond to the High Volatility Regime Period (Continued) 

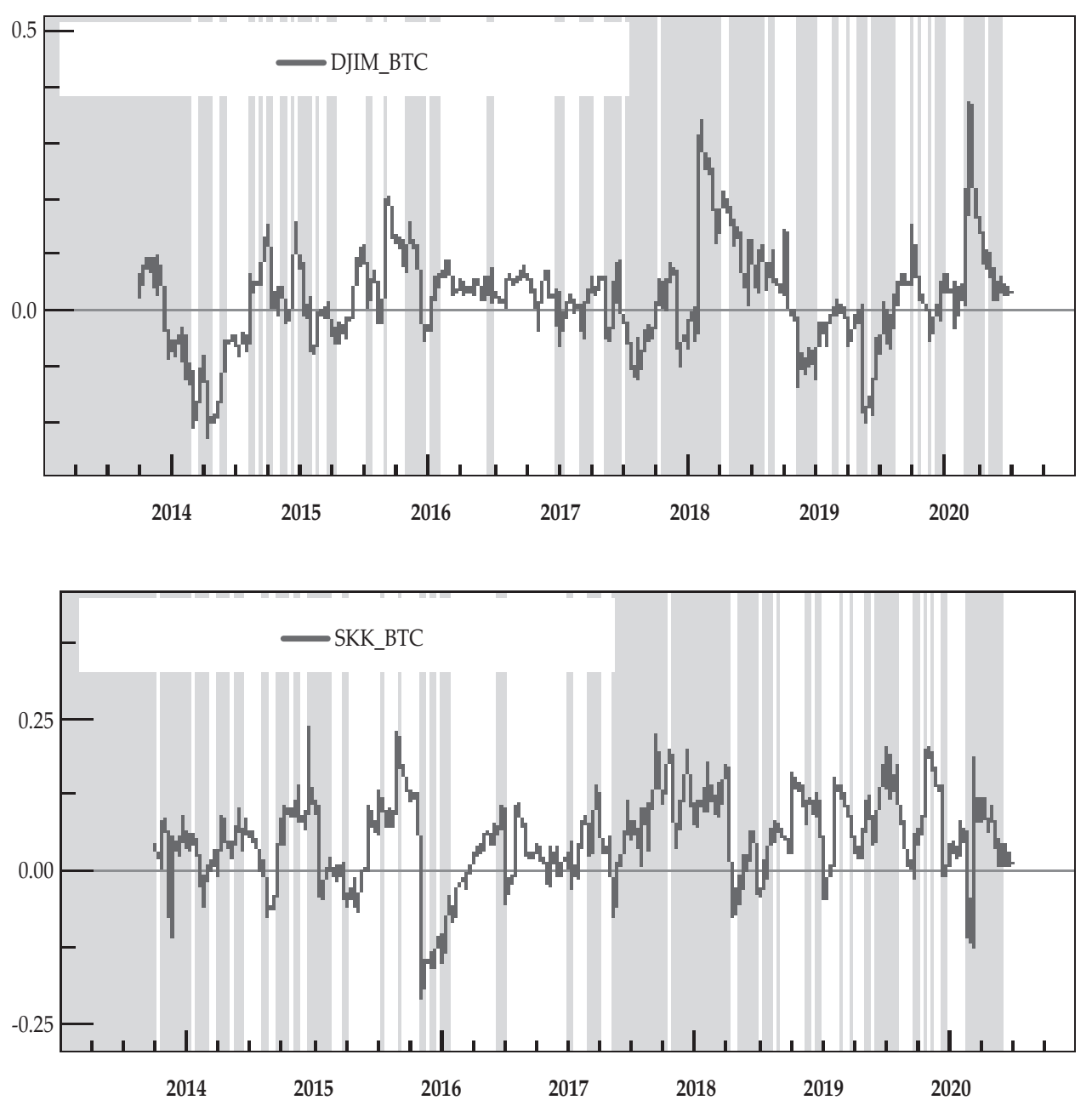

Figure $2 b$.

Estimated Dynamic Conditional Correlations. Shaded Areas Correspond to the High Volatility Regime Period (Continued) 


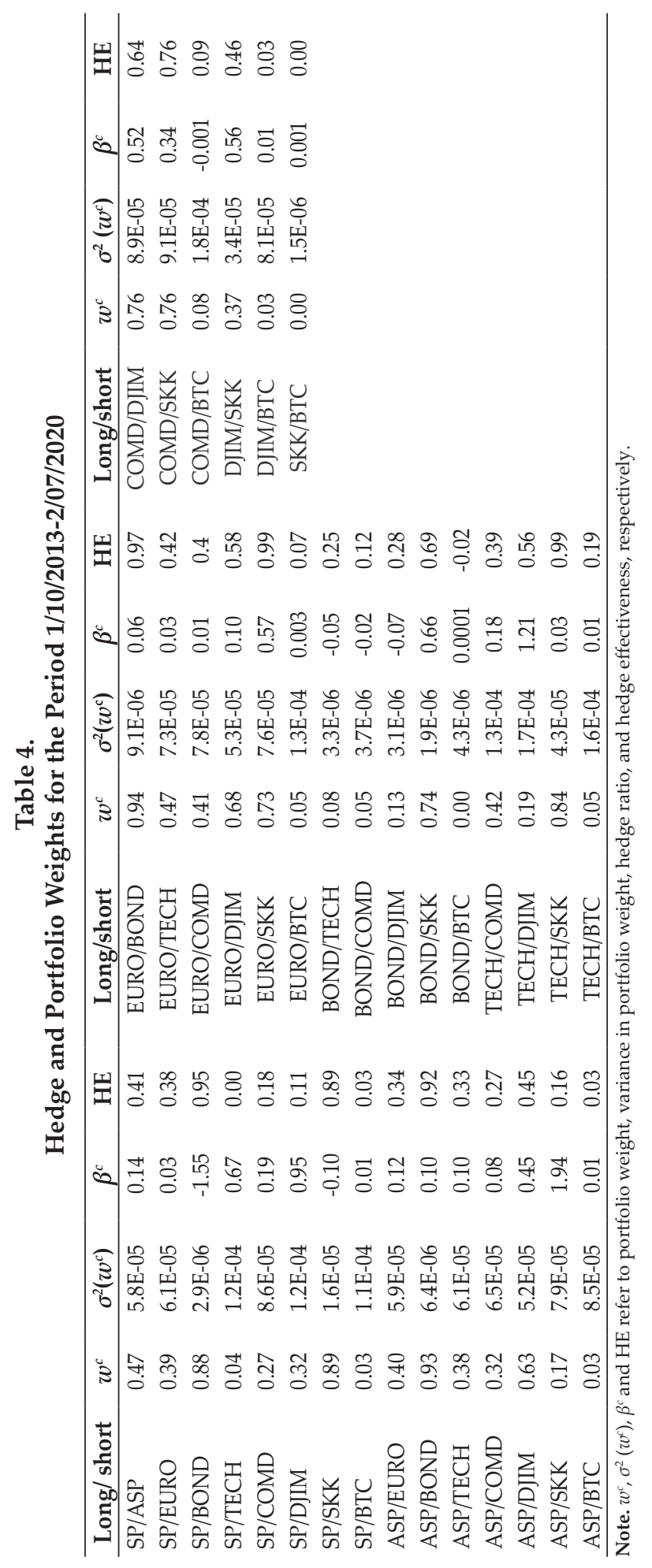




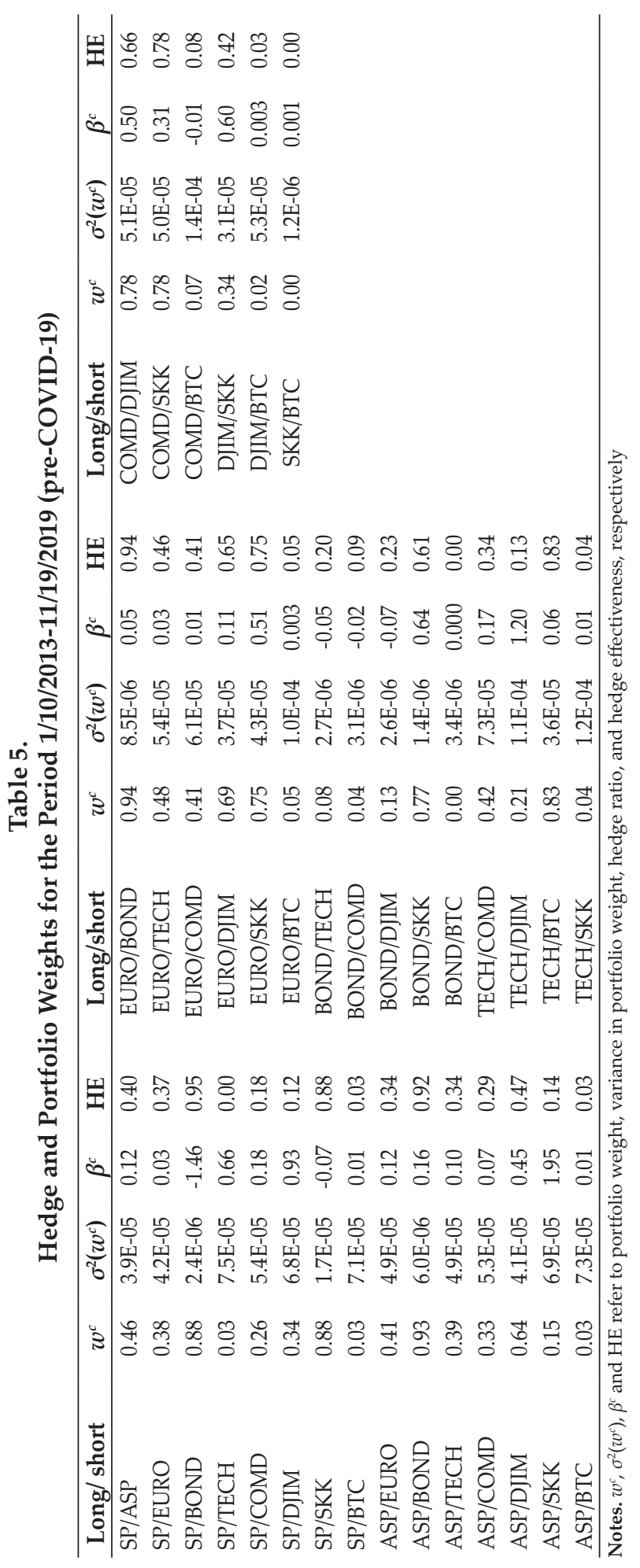




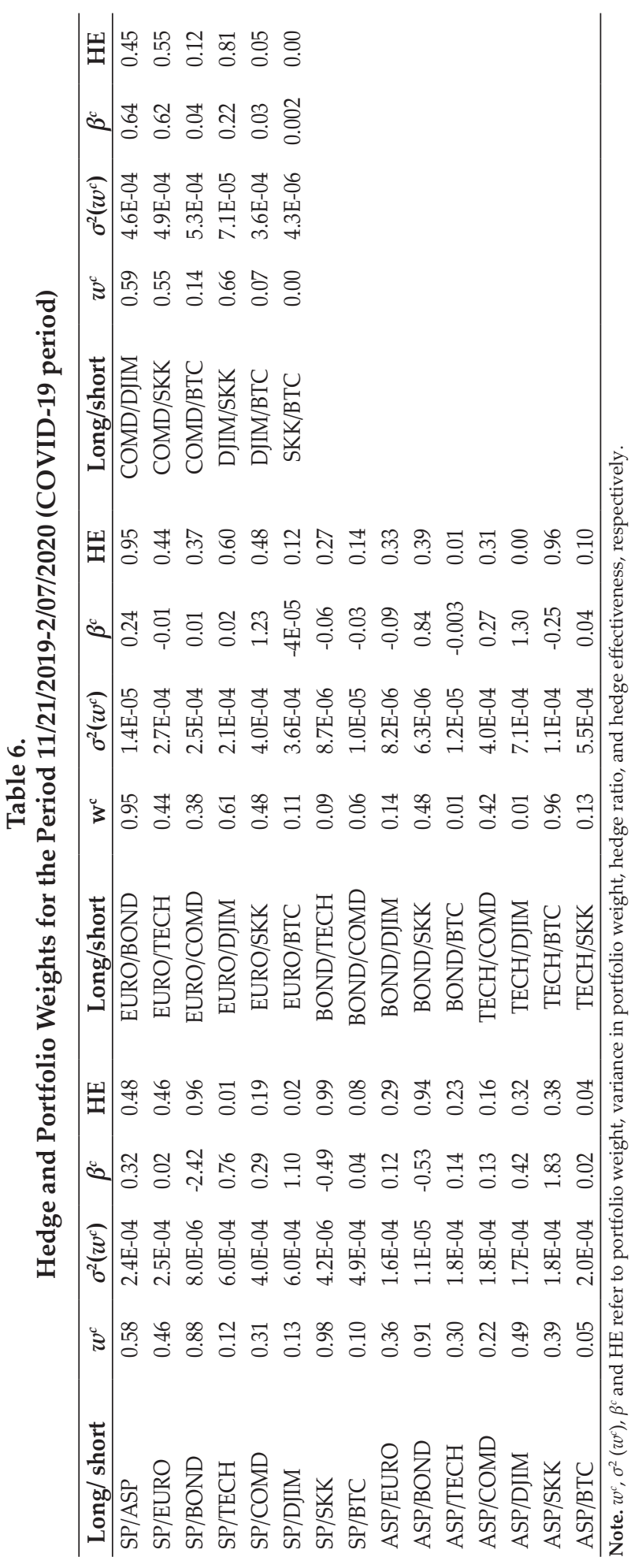




\subsection{Robustness Test}

For the robustness check, we propose the dynamic connectedness approach introduced by Diebold and Yilmaz (2014), based on the rolling-window expressed by the VAR model. This is useful for giving better understanding of the network effects among a system of variables.

Recently, studies including those of Antonakakis et al. (2018, 2019), Gabauer and Gupta (2018) and Korobilis and Yilmaz (2018) have combined the usual DY connectedness approach with TVP-VAR methodology. Accordingly, we used the following TVP-VAR(p):

$$
y_{t}=\gamma_{0 t}+\sum_{i=1}^{p} \lambda_{i t} x_{t-i}+\vartheta_{t}=\lambda_{t} z_{t}+\vartheta_{t}
$$

where $y_{t}$ is a vector of $k=10$ variables of interest (SP, ASP, EURO, BOND, TECH, COMD, DJIM, SKK, BTC, EMV_F); $Z_{t}=I \otimes ; \lambda_{t}=\operatorname{vec}\left(\left[\gamma_{0 t}{ }^{\prime}, \lambda_{1 t}^{\prime}, \cdots, \lambda^{\prime}{ }_{p t}\right]^{\prime}\right)$; and $\vartheta_{t} \sim \mathrm{N}\left(0, \Omega_{t}\right)$, with $\Omega_{t}$ being the $k \times k$ covariance matrix. In addition, Korobilis and Yilmaz (2018) assume that: $\lambda_{t}=\lambda_{t-1}+\eta_{t^{\prime}}$ with $\eta_{t} \sim N\left(0, \Psi_{t}\right)$.

Based on the TVP-VAR model estimated with the Minnesota prior method and the World representation of equation (14), a Vector Moving Average (VMA) was derived (Antonakakis et al., 2019) to estimate the following measures of spillovers:

Total spillover index $\operatorname{TS}(h)=\frac{\sum_{i, j=1, i \neq j}^{n} \tilde{\mathcal{Q}}_{i j}(h)}{\sum_{i, j=1}^{n} \widetilde{\mathcal{Q}}_{i j}(h)} \times 100$

Directional spillover index from variable $i$ to all other variables $j$

$D_{i \rightarrow j}(h)=\frac{\sum_{j=1, i \neq j}^{n} \tilde{\mathcal{Q}}_{j i}(h)}{\sum_{i, j=1}^{n} \tilde{\mathcal{Q}}_{i j}(h)} \times 100$

Directional spillover index from all other variables to variable $i$

$D_{i \leftarrow j}(H)=\frac{\sum_{j=1, i \neq j}^{n} \tilde{\mathcal{Q}}_{i j}(H)}{\sum_{i, j=1}^{n} \tilde{\mathcal{Q}}_{i j}(H)} \times 100$

Net spillover of variable $i N S_{i}=D_{i \rightarrow j}(h)-D_{i \leftarrow j}(H)$

Net pairwise spillover between variables $i$ and $j$

$N P S_{i j}(h)=\left[\frac{\tilde{\mathcal{Q}}_{i j}(h)}{\sum_{k=1}^{n} \tilde{\mathcal{Q}}_{i k}(h)}-\frac{\tilde{\mathcal{Q}}_{j i}(h)}{\sum_{k=1}^{n} \tilde{\mathcal{Q}}_{i k}(h)}\right]$

where $\mathcal{Q}_{i j}(h)=\frac{\sigma_{j j}^{-1} \sum_{h=0}^{H-1}\left(e^{\prime} \theta_{i} \theta_{h} e_{j}\right)^{2}}{\sum_{h=0}^{H-1}\left(e^{\prime}{ }_{i} \theta_{h} \Sigma \theta^{\prime} e_{i}\right)^{2}} ; \tilde{\mathcal{Q}}_{i j}(h)=\frac{Q_{i j}(h)}{\sum_{j=1}^{n} Q_{i j}(h)^{\prime}}, \sum_{j=1}^{n} \tilde{\mathcal{Q}}_{i j}(h)=1$; and

$\sum_{i, j=1}^{n} \tilde{\mathcal{Q}}_{i j}(H)=n$

\subsection{Analysis}

Tables 7 and 8 in Appendix 1 show the total static return volatility connectedness between the nine markets and the pandemic uncertainty measure. The estimate 
results show that the total return spillovers reached $41.17 \%$, implying moderate connectedness across all markets. The US market is the largest transmitter to other markets (103.7\%), followed by TECH (89.4\%) and the DJIM index $(85.2 \%)$. However, these markets are also the major net receivers of shocks from other markets, with net contributions equal to $39.1 \%, 26.6 \%$ and $24.5 \%$ respectively. Furthermore, the EMV_F is a net transmitter of shocks to other markets, with a net contribution equal to $4.5 \%$.

In general, the net pairwise spillover table gives investors useful insight into how they can diversify and protect their wealth in stress periods. Precisely, investors in Asia-Pacific markets or Europe are negatively affected by shocks from the U.S. stock markets (i.e., SP and TECH) and DJIM, so they should diversify and hedge their investments by using other assets such as bonds (conventional and Islamic bonds), COMD or bitcoin. Overall, investors must be attentive to the equity markets, since they appear to be the main source of return spillover shock to other markets.

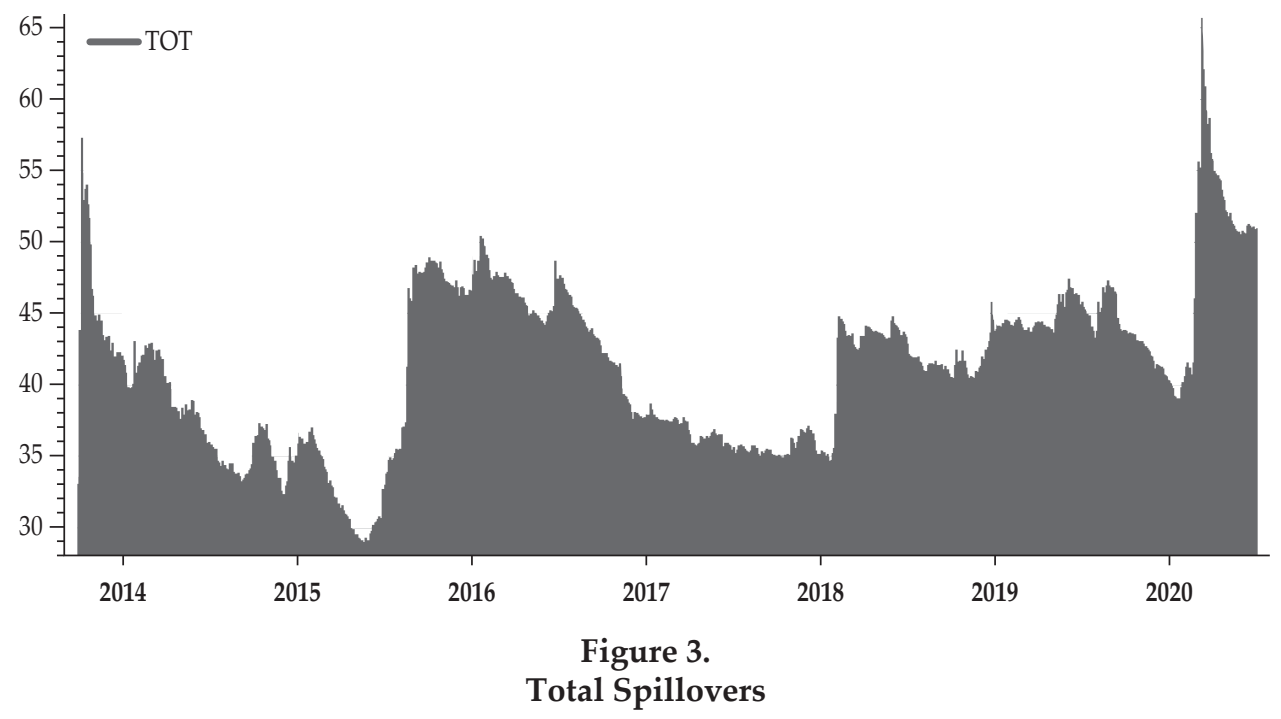

Figure 3 shows the time-varying of the total return spillovers. It can be seen that the level of these fluctuates within a broad range of $29 \%$ and $66 \%$, implying that the connectedness varies from moderate to strong magnitudes across markets in responses to various events. It is also clear that total connectedness peaked during the ongoing COVID-19 pandemic in mid-March 2020. Therefore, the results indicate contagion effects among the markets under consideration.

Figures A1 and A2 in Appendix 2 show the bilateral link between the pandemic uncertainty and the other price returns. The graphical results are in line with our findings in Table 6 and the conclusion of Baker et al. (2020) and Altig et al. (2020). Indeed, the net pairwise connectedness between the pandemic uncertainty and most asset classes reached a greater intensity after the onset of the COVID-19 pandemic, which can affect the asset allocation of different investors. 


\section{CONCLUSION AND RECOMMENDATIONS}

\subsection{Conclusion}

This paper has investigated the effects of the recent COVID-19 pandemic on asset allocation in three regional equity markets, namely the US, Europe, and AsiaPacific regions. Moreover, we have examined the diversifier, hedge and safe-haven properties of six assets, namely the Dow Jones Islamic Equity Index, bitcoin, The S\&P GSCI Commodity Index, U.S. treasury bills, the S\&P 500 Technology Index, and the Dow Jones Sukuk Global Index against the risk of these three conventional stock markets.

Using a two-regime Markov Switching (MS(2)) model, we found that bonds (U.S. treasury bills) could act as a diversifier, hedge and safe-haven asset against stocks in different regional financial markets, while aggregate commodity indices, the technology index and Islamic instruments enabled better hedging against European stock market risk for the overall sample.

By employing the DCC-GARCH model proposed by Engle (2002) to construct the hedge ratios and optimal portfolio weights, we found that only bonds could be considered as good safe-haven assets in the ongoing crisis. Sukuk is also a better safe haven asset, but only against the risk of the S\&P 500, S\&P 500 Technology Index and Dow Jones Islamic Index. Regarding the Islamic Equity Index, it serves as a hedging instrument for bond investors, while Sukuk can be a safe haven for them.

The robustness check using the TVP-VAR model indicated that COVID-19 pandemic uncertainty has more influence on the three equity regional indices than the other assets and then the asset allocation. These results can help investors to decide on the best strategy to overcome the ongoing pandemic crisis.

The study has several limitations. First, it does not make a time-frequency analysis, which can be performed by using novel wavelet tools. Second, the study does not examine other safe haven assets such as gold or US dollars.

\subsection{Recommendations}

Despite these limitations, the findings could have important implications for individual and institutional investors, as well as for policymakers. While sovereign bonds and sukuk provide some portfolio safety, this research has found that cryptocurrencies, commodities, technology and equities do not offer any substantial benefit. These results could have important consequences for the research area, as they both prove and disprove the findings of several recent studies on the impact of the ongoing health crisis. Furthermore, the study examines different relationships between assets that have not been explored earlier, such as the technology sector, Islamic investment certificates, commodities and the pandemic uncertainty index.

Our findings could also be important for regulators when implementing safety plans to reduce the economic and financial impacts of the ongoing COVID-19 crisis, by preventing spillovers or contagion among the components of the financial system. Finally, our study suggests that different regional investors may prefer Sukuk to mitigate their risk during the present situation. Institutional investors (e.g. Bank Indonesia) could also continue to take advantages from Sukuk as an alternative source of funds with low cost and risk. 
This work could be extended to cover the properties of other assets (e.g. US dollars and crude oil), with the use of frequency set data.

\section{REFERENCES}

Albulescu, C. T. (2021). COVID-19 and the United States financial markets' volatility. Finance Research Letters, 38(January 2021), 101699. https://doi. org/10.1016/j.frl.2020.101699.

Altig, D., Baker, S., Barrero J. M., Bloom, N., Bunn, P., \& Chen, S. (2020). Economic uncertainty before and during the COVID-19 pandemic. Journal of Public Economics, 191(November 2020), 104274. doi: 10.1016/j.jpubeco.2020.104274.

Antonakakis, N., Chatziantoniou, I. \& Gabauer, D. (2019). Cryptocurrency market contagion: Market uncertainty, market complexity, and dynamic portfolios. Journal of International Financial Markets, Institutions and Money, 61(July 2019), 37-51.

Antonakakis, N., Gabauer, D., Gupta, R. \& Plakandaras, V. (2018). Dynamic connectedness of uncertainty across developed economies: A time-varying approach. Economics Letters, 166(May 2018), 63-75.

Ashraf, D. (2013). Performance evaluation of Islamic mutual funds relative to conventional funds: Empirical evidence from Saudi Arabia. International Journal of Islamic and Middle Eastern Finance and Management, 6(2), 105-121.

Ashraf, D., Rizwan, M. S., \& Ahmad, G. (2020). Islamic equity investments and the COVID-19 pandemic (May 27, 2020). Available at SSRN: http:/dx.doi. org/10.2139/ssrn.3611898.

Baker, S. R., Bloom, N., Davis, S. J., Kost, K. J., Sammon, M. C., \& Viratyosin, T. (2020). The unprecedented stock market impact of COVID-19. National Bureau of Economic Research Working Paper Series (No. 26945).

Baur, D. G., \& Lucey, B. M. (2010). Is gold a hedge or a safe haven? An analysis of stocks, bonds and gold. Financial Review, 45(2), 217-229. https://doi.org/10.1111/ j.1540-6288.2010.00244.x.

Baur, D. G., \& McDermott, T. K. (2010). Is gold a safe haven? International evidence. Journal of Banking \& Finance, 34(8), 1886-1898. https://doi.org/10.1016/j. jbankfin.2009.12.008.

Bhuiyan, R. A., Rahman M. P., Saiti B., \& Ghan, G. M. (2018). Financial integration between sukuk and bond indices of emerging markets: Insights from wavelet coherence and multivariate-GARCH analysis. Borsa Istanbul Review, 18(3), 218230.

Bouri, E., Cepni, O., Gabauer, D., \& Gupta, R. (2020). Return connectedness across asset classes around the COVID-19 outbreak. International Review of Financial Analysis, 73(January 2021), 101646. https://doi.org/10.1016/j.irfa.2020.101646.

Rom, B. M., \& Ferguson, K. W. (1993). Post-modern portfolio theory comes of age. The Journal of Investing Winter, 2(4), 27-33. https://doi.org/10.3905/joi.2.4.27.

Chan, K. F., Treepongkaruna, S., Brooks, R., \& Gray, S. (2011). Asset market linkages: Evidence from financial, commodity and real estate assets. Journal of Banking \& Finance, 35(6), 1415-1426.

Cheema, M. A., Faff, R. W., \& Szulczuk, K. (2020). The 2008 global financial crisis and COVID-19 pandemic: How safe are the safe haven assets? Covid Economics, Vetted and Real-Time Papers, (34), 88-115. http://dx.doi.org/10.2139/ssrn.3642945. 
Ciaian, P., Rajcaniova, M., \& Kancs, D. A. (2016). The economics of BitCoin price formation. Applied Economics, 48(19), 1799-1815.

Conlon, T., \& McGee, R. (2020). Safe haven or risky hazard? Bitcoin during the COVID-19 bear market. Finance Research Letters, 35(July 2020), 101607.

Constantinides, G. (1986). Capital market equilibrium with transaction costs. Journal of Political Economy, 94(4), 842-62.

Corbet, S., Larkin, C., \& Lucey, B. (2020). The contagion effects of the covid-19 pandemic: Evidence from gold and cryptocurrencies. Finance Research Letters, 35(July 2020), 101554.

Diebold, F. X., \& Yilmaz, K. (2014). On the network topology of variance decompositions: Measuring the connectedness of financial firms. Journal of Econometrics, 182(1), 119-134.

Engle, R. (2002). Dynamic conditional correlation: A simple class of multivariate generalized autoregressive conditional heteroskedasticity models. Journal of Business E Economic Statistics, 20(3), 339-350.

Faugère, C. (2013). A new characterization of gold as store of wealth across monetary standards and in a global crisis (July 2013). Available at SSRN: http:// dx.doi.org/10.2139/ssrn.2299022.

Fleming, J., Kirby, C \& Ostdiek, B. (1998). Information and volatility linkages in the stock, bond, and money markets. Journal of Financial Economics, 49(1), 111-137.

Gabauer, D., \& Gupta, R. (2018). On the transmission mechanism of country-specific and international economic uncertainty spillovers: Evidence from a TVP-VAR connectedness decomposition approach. Economics Letters, 171(October 2018), 63-71.

Gârleanu, N. \& Pedersen, L. H. (2016). Dynamic portfolio choice with frictions. Journal of Economic Theory, 165(September 2016), 487-516.

Goodell, J. W., \& Goutte, S. (2021). Co-movement of COVID-19 and Bitcoin: Evidence from wavelet coherence analysis. Finance Research Letters, 38(January 2021), 101625.

Hartmann, P., Straetmans S. \& de Vries C. G. (2004). Asset market linkages in crisis periods. Review of Economics and Statistics, 86(1), 313-326.

Heaton, J. \& Lucas, D. (1997). Market frictions, savings behavior, and portfolio choice. Macroeconomic Dynamics, 1(1), 76-101.

Huang, X. (2008). Portfolio selection with a new definition of risk. European Journal of Operational Research, 186(1), 351-357.

Kaul, A., \& Sapp, S. (2006). Y2K fears and safe haven trading of the US dollar. Journal of International Money and Finance, 25(5), 760-779.

Korobilis, D., \& Yilmaz, K. (2018). Measuring dynamic connectedness with large Bayesian VAR models (January 10, 2018). Available at SSRN: http://dx.doi. org/10.2139/ssrn.3099725.

Lintner, J. (1965). The Valuation of risk assets and the selection of risky investments in stock portfolios and capital budgets. The Review of Economics and Statistics, 47(1), 13-37.

Liu, H., Manzoor, A., Wang, C., Zhang, L., \& Manzoor, Z. (2020). The COVID-19 outbreak and affected countries stock markets response. International Journal of Environmental Research and Public Health, 17(8), 2800. https://doi.org/10.3390/ ijerph17082800. 
Markowitz, H. (1952) Portfolio selection. The Journal of Finance, 7(1), 77-91. https:// doi.org/10.1111/j.1540-6261.1952.tb01525.x.

Markowitz, H. (1959). Portfolio selection: Efficient diversification of investment. New York: John Wiley \& Sons.

McCown, J. R., \& Zimmerman, J. R. (2006). Is gold a zero-beta asset? Analysis of the investment potential of precious metals. Analysis of the Investment Potential of Precious Metals (July 24, 2006). Available at SSRN: https://ssrn.com/ abstract $=920496$.

Merton, R. (1971). Optimum consumption and portfolio rules in a continuous-time model. Journal of Economic Theory, 3(4), 373-413.

Mossin, J. (1966). Equilibrium in a capital asset market. Econometrica, 34(4), 768783. http://dx.doi.org/10.2307/1910098.

Noeth, B. J., \& Sengupta, R. (2010). Flight to safety and US treasury securities. The Regional Economist, 18(3), 18-19.

Ramelli, S., \& Wagner, A. F. (2020). Feverish stock price reactions to the novel coronavirus. Forthcoming, Review of Corporate Finance Studies, Swiss Finance Institute Research Paper (No.20-12). Available at SSRN: https://ssrn.com/ abstract $=3550274$.

Rasiah, D. (2012). Post-modern portfolio theory supports diversification in an investment portfolio to measure investment's performance. Journal of Finance and Investment Analysis, 1(1), 69-91.

Rockafellar, R.T. \& Uryasev, S. (2002). Conditional value-at-risk for general loss distributions. Journal of Banking and Finance, 26(7), 1443-1471.

Samuelson, P.A. (1969). Lifetime portfolio selection by dynamic stochastic programming. The Review of Economics and Statistics, 51(3), 239-246. https://doi. org/10.2307/1926559.

Shahbaz, M., Tahir M. I., Ali I., \& Rehman, I. U. (2014). Is gold investment a hedge against inflation in Pakistan? A co-integration and causality analysis in the presence of structural breaks. The North American Journal of Economics and Finance, 28(April 2014), 190-205.

Shahzad, S. J. H., Aloui, C., Jammazi, R., \& Shahbaz, M. (2019). Are Islamic bonds a good safe haven for stocks? Implications for portfolio management in a timevarying regime-switching copula framework. Applied Economics, 51(3), 219238.

Shahzad, S. J. H., Bouri, E., Roubaud, D., Kristoufek, L., \& Lucey, B. (2019). Is Bitcoin a better safe-haven investment than gold and commodities? International Review of Financial Analysis, 63(May 2019), 322-330.

Sharpe, W. F. (1964) Capital asset prices: A theory of market equilibrium under conditions of risk. Journal of Finance, 19(3), 425-442.

Sherman, E. J. (1986). Gold investment: Theory and application. New York: Prentice Hall.

Śmiech, S., \& Papież, M. (2017). In search of hedges and safe havens: Revisiting the relations between gold and oil in the rolling regression framework. Finance Research Letters, 20(February 2017), 238-244.

Stensås, A., Nygaard, M. F., Kyaw, K., \& Treepongkaruna, S. (2019). Can bitcoin be a diversifier, hedge or safe haven tool?. Cogent Economics E Finance, 7(1), 1593072. 
Urquhart, A., \& Zhang, H. (2019). Is Bitcoin a hedge or safe haven for currencies? An intraday analysis. International Review of Financial Analysis, 63(May 2019), 49-57.

Yarovaya, L., Elsayed, A. H., \& Hammoudeh, S. M. (2020). Searching for safe havens during the COVID-19 pandemic: Determinants of spillovers between Islamic and conventional financial markets (June 11, 2020). Available at SSRN: https://ssrn.com/abstract=3634114.

Zhang, D., Hu, M., \& Ji, Q. (2020). Financial markets under the global pandemic of COVID-19. Finance Research Letters, 36(October 2020), 101528. 


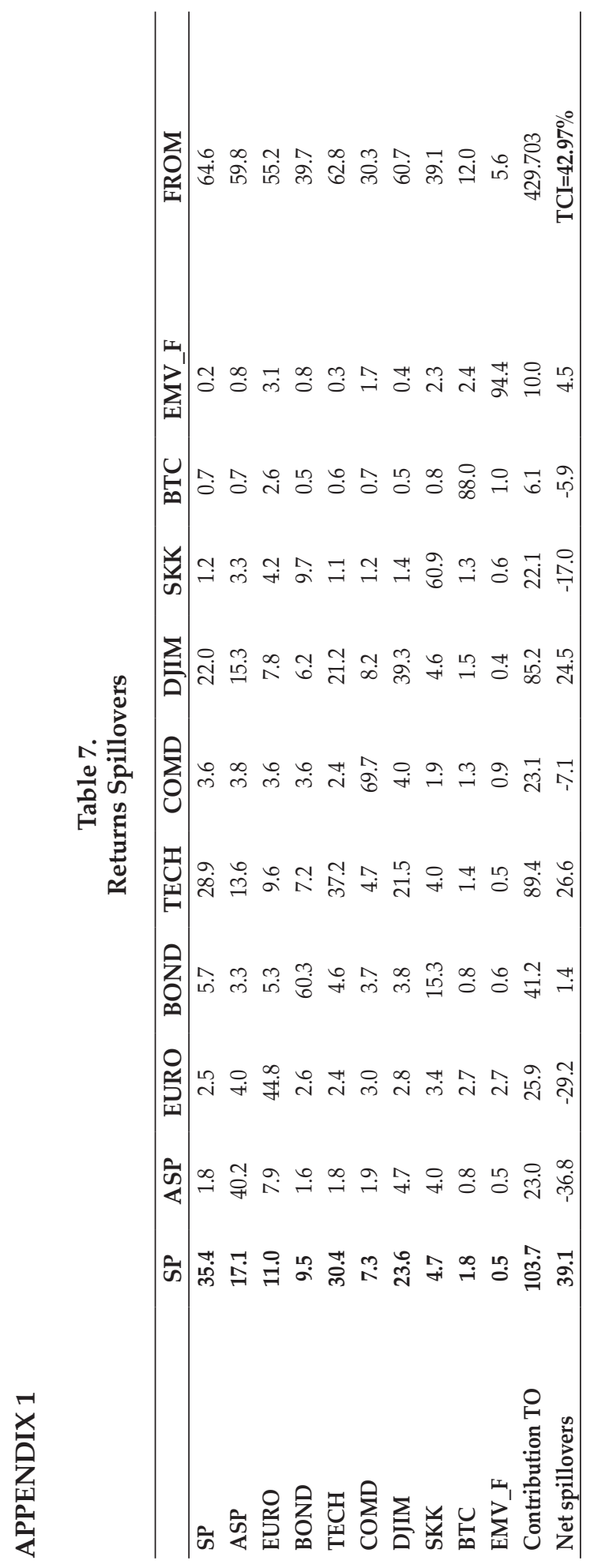




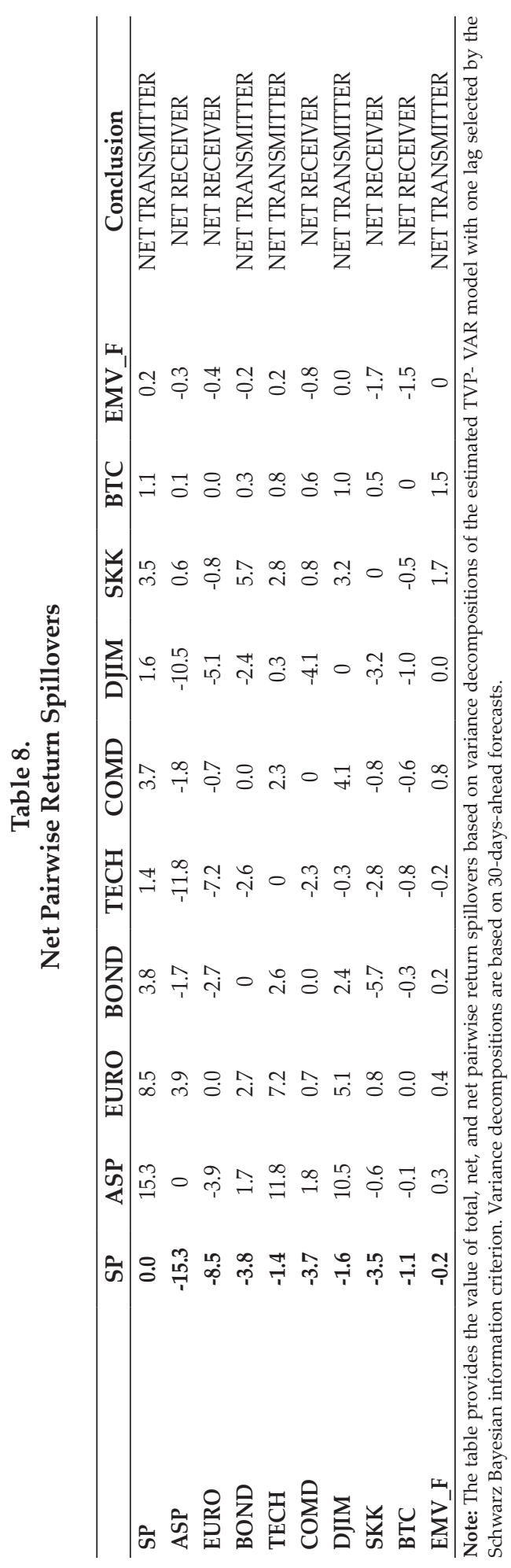




\section{APPENDIX 2}
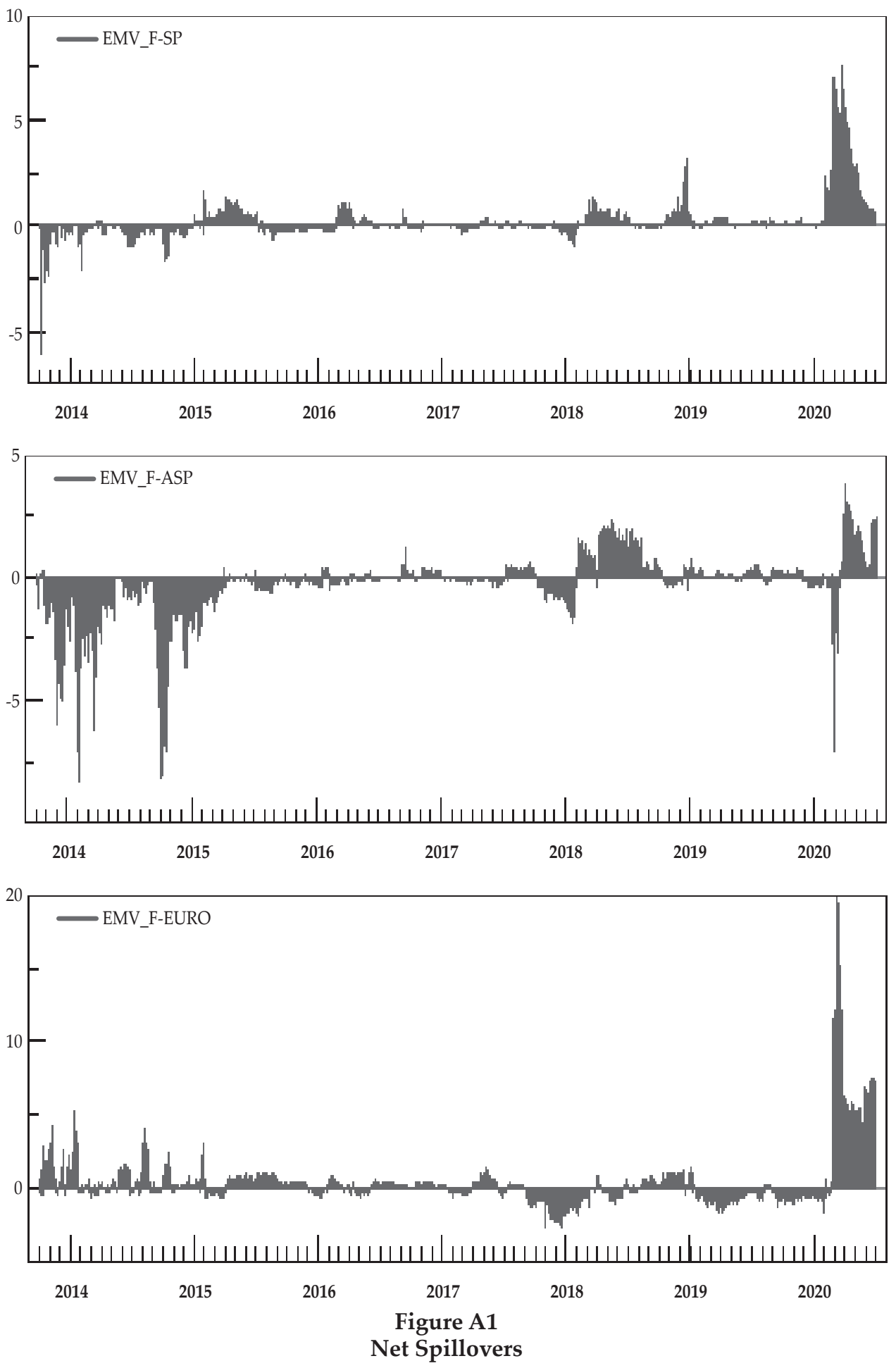

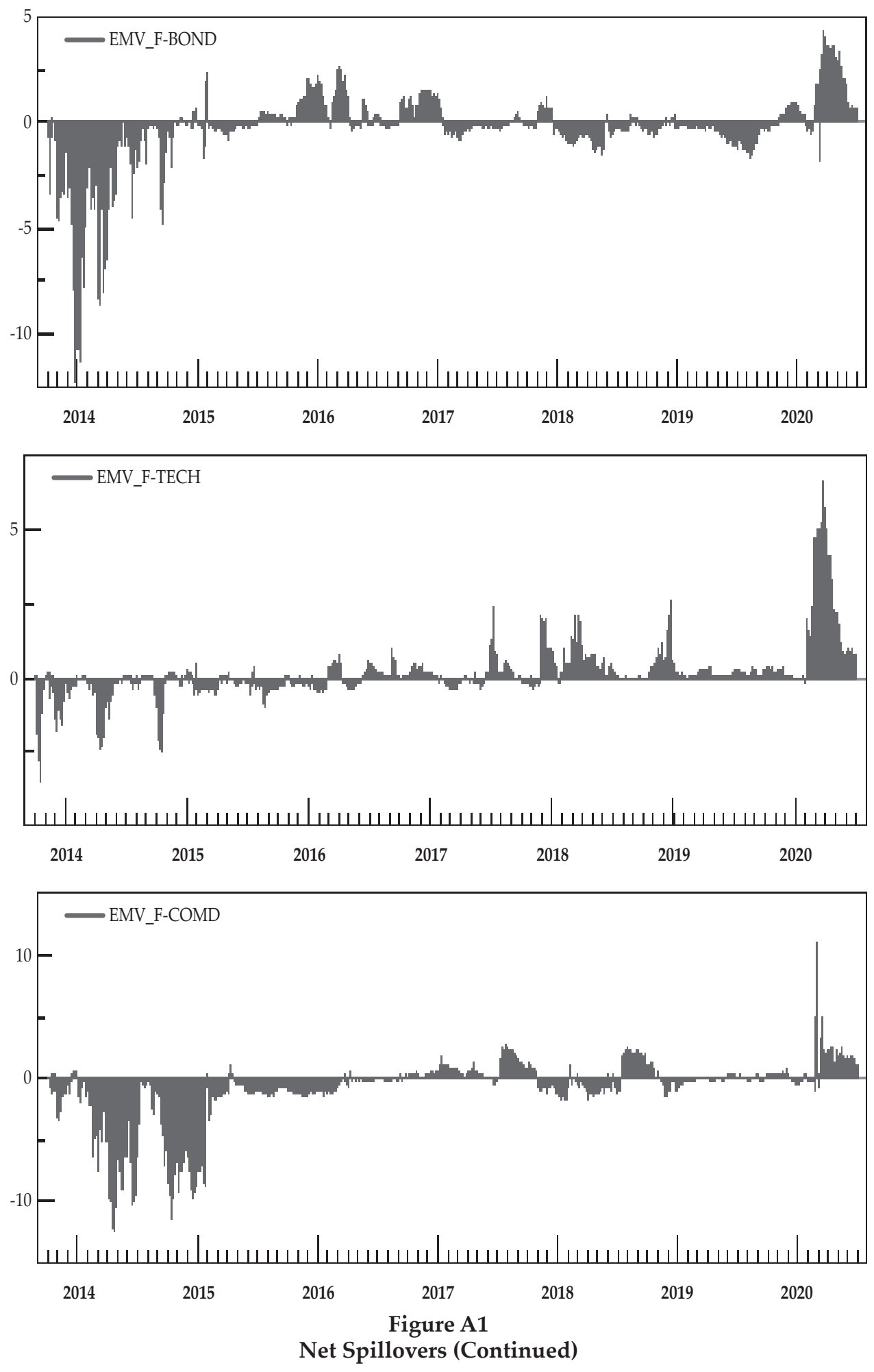

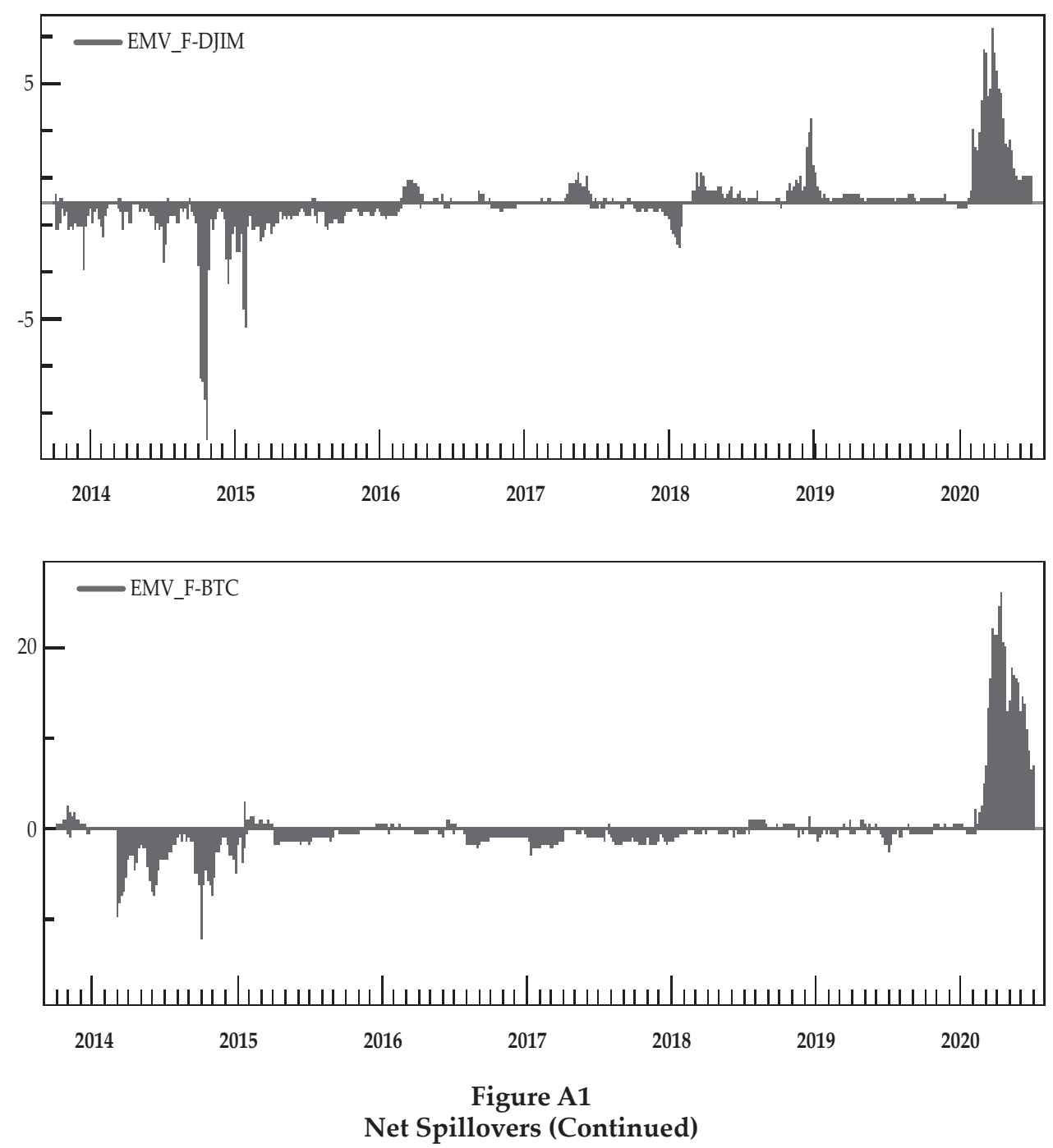

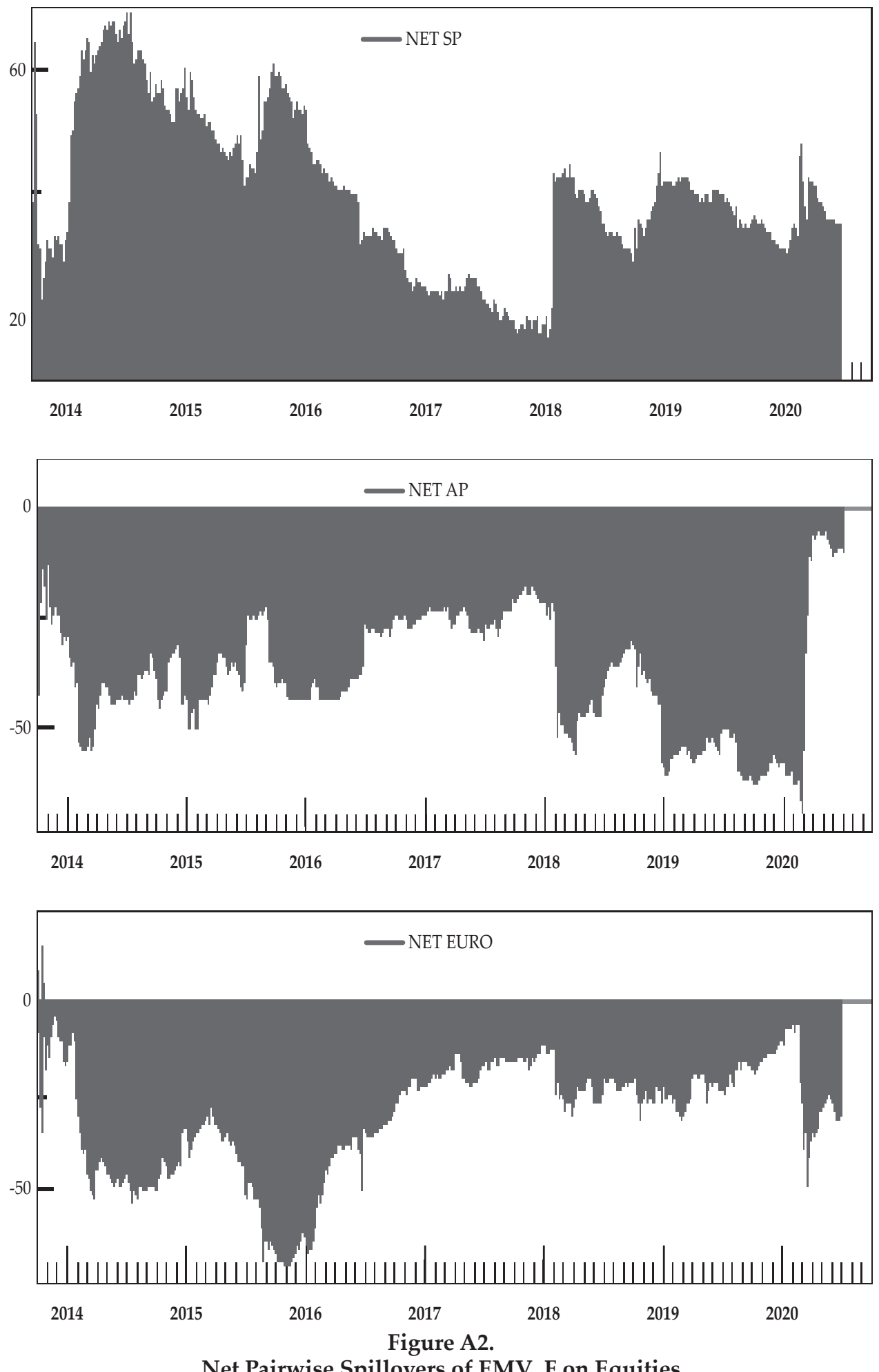

Net Pairwise Spillovers of EMV_F on Equities 

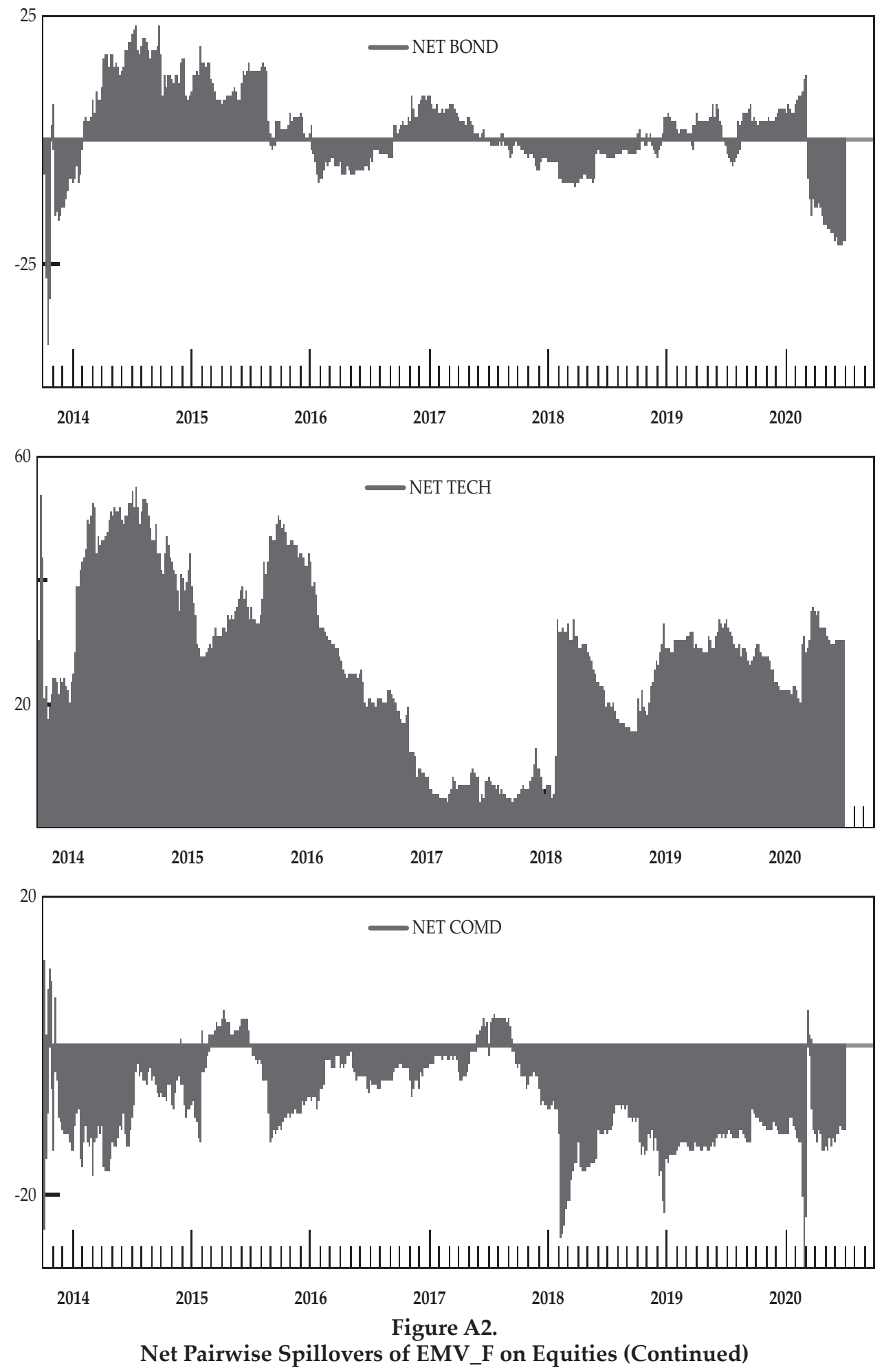

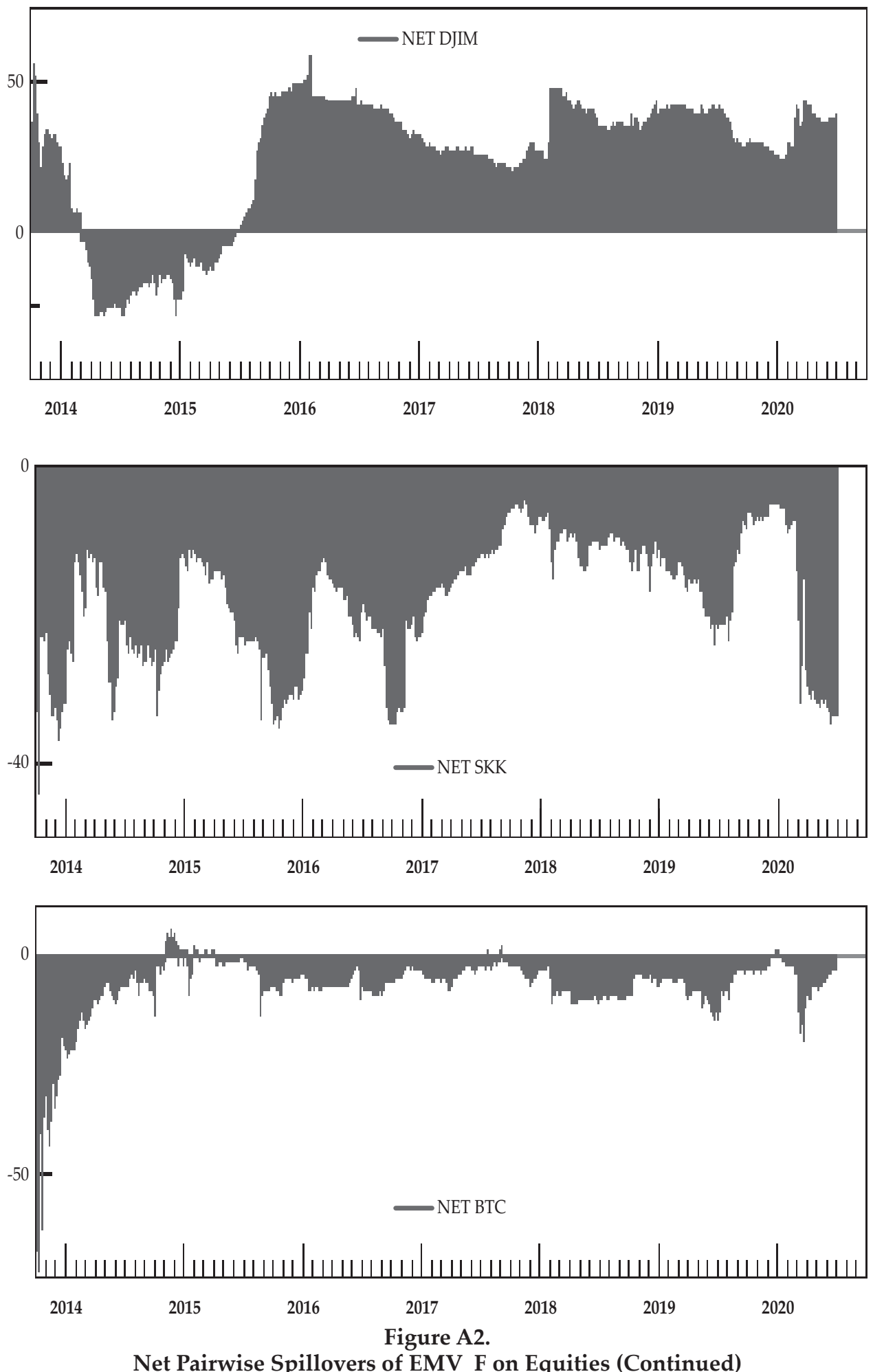

Net Pairwise Spillovers of EMV_F on Equities (Continued) 


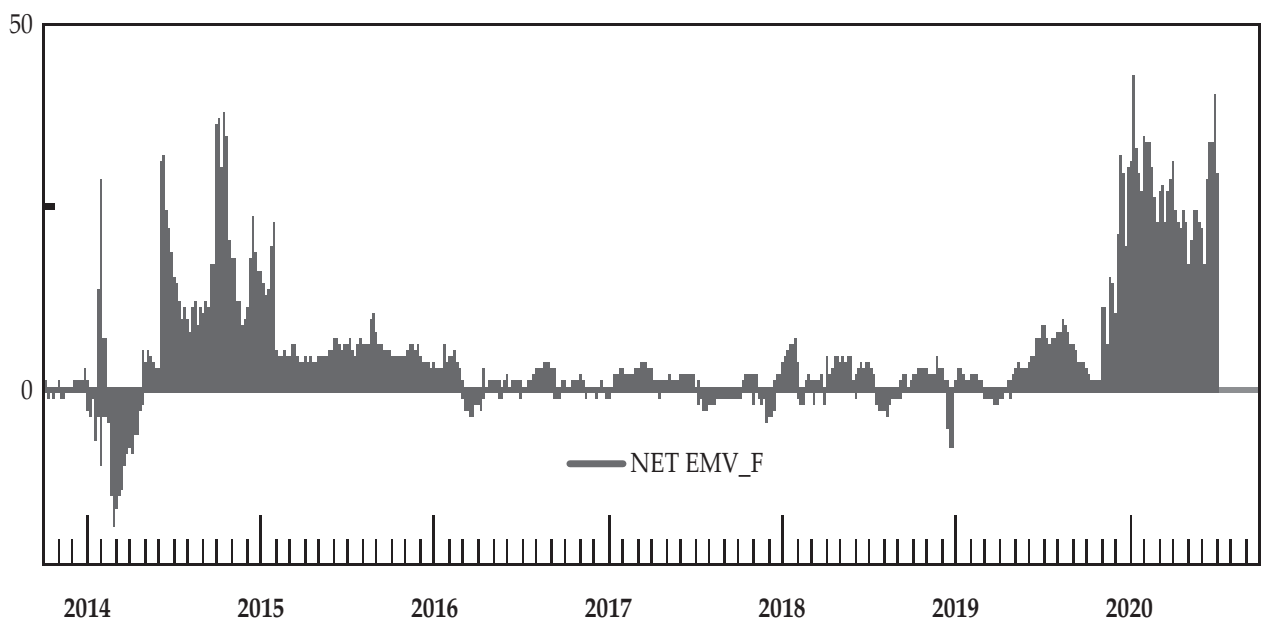

Figure A2.

Net Pairwise Spillovers of EMV_F on Equities (Continued) 
This page is intentionally left blank 